\title{
Non-Alcoholic Fatty Liver Disease (NAFLD) in Patients with Psoriasis: A Review of the Hepatic Effects of Systemic Therapies
}

\author{
Deepak MW Balak ${ }^{1,2}$ \\ Stefano Piaserico ${ }^{3}$ \\ Ismail Kasujee ${ }^{4}$
}

'Department of Dermatology, LangeLand Ziekenhuis, Zoetermeer, the Netherlands; ${ }^{2}$ Department of Dermatology, Ghent University Hospital, Ghent, Belgium; ${ }^{3}$ Dermatology Unit, Department of Medicine, University of Padova, Padova, Italy; ${ }^{4}$ Almirall GMA, Barcelona, Spain
Correspondence: Deepak MW Balak Email balak.dmw@gmail.com

\begin{abstract}
There is increasing interest in the association between psoriasis and non-alcoholic fatty liver disease (NAFLD), which is a prevalent liver disease characterized by excessive fat storage and inflammation that can progress to fibrosis and cancer. Patients with psoriasis have a two-fold higher risk to develop NAFLD and a higher risk to progress to more severe liver disease. Psoriasis and NAFLD share common risk factors such as smoking, alcohol consumption, and the presence of metabolic syndrome and its component disorders. In addition, both psoriasis and NAFLD hinge upon a systemic low-grade inflammation that can lead to a vicious cycle of progressive liver damage in NAFLD as well as worsening of the underlying psoriasis. Other important shared pathophysiological pathways include peripheral insulin resistance and oxidative stress. NAFLD should receive clinical awareness as important comorbidity in psoriasis. In this review, we assess the recent literature on the epidemiological and pathophysiological relationship of psoriasis and NAFLD, discuss the clinical implications of NAFLD in psoriasis patients, and summarize the hepatotoxic and hepatoprotective potential of systemic psoriasis therapies.
\end{abstract}

Keywords: non-alcoholic fatty liver disease, psoriasis, fumaric acid esters, Nrf2-activation

\section{Introduction}

Psoriasis is a chronic, immune-mediated inflammatory dermatological disease that affects nearly 150 million people worldwide. It is associated with a significant disease burden, a marked negative impact on patients' quality of life, ${ }^{1}$ and places enormous pressure on health systems globally. ${ }^{2-4}$ In recent years attention has focused on the inflammatory processes underpinning the pathophysiological changes in psoriasis. In particular, cutaneous inflammation in psoriasis is linked to chronic systemic low-grade inflammation, which is thought to underlie the associations of psoriasis with comorbidities such as psoriatic arthritis, mood disorders including depression, and a range of cardiometabolic disorders that include myocardial infarction, hypertension, obesity, type 2 diabetes, non-alcoholic fatty liver disease (NAFLD), dyslipidemia, and hyperuricemia. ${ }^{3,5}$

One comorbidity of psoriasis that is increasingly recognized as clinically relevant is NAFLD. ${ }^{3,6,7}$ NAFLD is characterized by excessive hepatic fat storage and is strongly associated with obesity, type 2 diabetes, and metabolic syndrome. Over time, NAFLD can progress to a more severe, inflammatory disease termed nonalcoholic steatohepatitis (NASH) and eventually to the development of cirrhosis. ${ }^{8}$ NAFLD is the most common liver disease and its prevalence is rising rapidly. US 
studies have reported a $10-35 \%$ prevalence in the general population with an average of between 20 and $30 \%{ }^{9}$ The global prevalence of NAFLD is estimated to be $25 \% .{ }^{10,11}$ The presence of NASH in the general population is difficult to ascertain since it can be confirmed only by liver biopsy. However, rates between 1.5 and $6.5 \%$ have been reported. ${ }^{9,10,12} \mathrm{NASH}$ is a potentially progressive disease that can lead to cirrhosis in $12-25 \%$ of cases within a $10-$ year period, and it is associated with increased risks for hepatocellular carcinoma and cardiovascular- and liverrelated deaths. ${ }^{8,13,14}$

NAFLD has been shown to occur 1.5 to 3 times more frequently in patients with psoriasis than in the general population. ${ }^{3,11,15}$ Prevalences of NAFLD ranging up to $65 \%$ have been reported in this patient population. ${ }^{16}$ The increased risk of NAFLD in psoriasis patients is not surprising, as the two diseases share a common link with the metabolic syndrome. However, there may be an association between psoriasis and NAFLD that is independent from the metabolic syndrome, hinging directly on the chronic low-grade systemic inflammatory burden characteristic of these two conditions. ${ }^{5}$ Importantly, when psoriasis co-occurs with NAFLD the disease severity and morbidity of both conditions may be greater. ${ }^{17}$

The aim of this review is to evaluate the recent literature on the clinical and pathophysiological associations linking psoriasis with NAFLD, independently of the metabolic syndrome, focusing on the chronic low-grade inflammation underpinning the two disorders. Second, we aimed to assess the potential hepatotoxic and hepatoprotective effects of currently approved systemic psoriasis therapies, in particular dimethyl fumarate (DMF), an oral small molecule with pleiotropic effects that could positively impact NAFLD.

\section{Search Strategy}

For this narrative review, a targeted search of PubMed up to 14 July 2021 was conducted using the following search strategies: 'psoriasis' with (a) "non-alcoholic fatty liver disease/NAFLD" $(\mathrm{n}=96)$, (b) "hepatotoxicity" $1 / 1 / 2010$ to $14 / 7 / 2021(\mathrm{n}=72)$, and (c) "hepatoprotection" ( $\mathrm{n}=14)$; "psoriasis treatment" with (a) "hepatotoxicity" $1 / 1 / 2010$ to $14 / 7 / 2021(\mathrm{n}=68)$, and (b) hepatoprotection $(\mathrm{n}=11)$. Relevant papers were identified by reviewing abstracts or full papers (if required), and by contributory articles cited in the selected references. The bibliography was augmented by key articles known to the authors and, finally, by individual drug data identified via a search of LiverTox (https://www.ncbi.nlm.nih.gov/books/ NBK548744/).

\section{Non-Alcoholic Fatty Liver Disease: Definitions and Spectrum}

NAFLD is the most common chronic liver disease worldwide and, in the majority of patients, is strongly associated with metabolic risk factors such as obesity, diabetes mellitus, and dyslipidemia. Individuals with metabolic syndrome have a 4 - to 11 -fold increased risk of developing NAFLD. ${ }^{18}$ NAFLD is characterized by fat deposition in the liver, in the absence of viral diseases such as hepatitis B or C, significant alcohol consumption, use of steatosis-stimulating drugs such as methotrexate, steroids, amiodarone and tamoxifen, or certain hereditary conditions including Wilson's disease and cholesteryl ester storage syndrome. ${ }^{19,20}$

NAFLD includes a wide spectrum of liver conditions with two main histological forms: simple hepatic steatosis (fat deposited, but no damage to liver cells) and NASH, which is characterized by hepatic inflammation that can lead to liver fibrosis. The aberrant pathophysiological processes underlying the progression to NASH are not fully understood, but are thought to include an imbalance of fatty acid metabolism leading to steatosis, and an elevated inflammatory response as a result of oxidative/metabolic stress and dysregulated cytokine production. ${ }^{21}$ Potential consequences of these processes are the development of lobular hepatitis with perivenular/pericellular (chicken wire) fibrosis, NAFLD-associated cirrhosis and liver failure and, albeit infrequently, hepatocellular carcinoma (Figure 1). ${ }^{5,22}$

In terms of clinical presentation, the majority of NAFLD cases are either asymptomatic or have nonspecific symptoms such as fatigue and abdominal pain, and/or abnormal liver function test results. NAFLD can be diagnosed if $>5 \%$ hepatic steatosis is shown by liver ultrasound in the absence of excessive alcohol use. ${ }^{8}$ The assessment for potential NASH requires additional testing using non-invasive assessment for liver fibrosis such as vibration-controlled transient elastography or magnetic resonance elastography. However, to confirm the diagnosis 


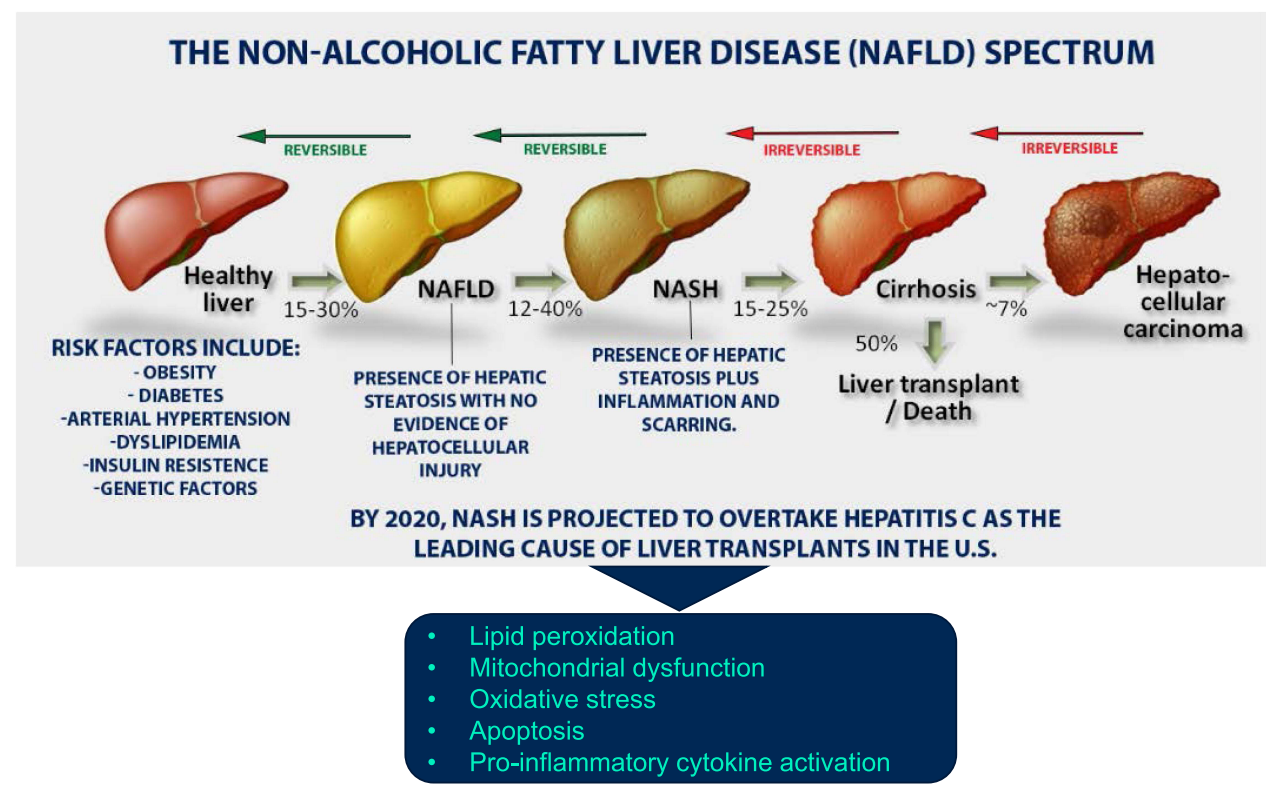

Figure I Spectrum of non-alcoholic fatty liver disease (NAFLD). Data from these studies. ${ }^{5,22}$

of NASH, histopathologic assessment of a liver biopsy is required.

Treatment of NAFLD is limited to optimal management of comorbid conditions such as type 2 diabetes and dyslipidemia, and lifestyle modifications aiming at $7-10 \%$ weight loss through caloric restriction and exercise. ${ }^{8}$ Weight loss and increased physical activity/exercise can help normalize liver enzyme levels, reduce hepatic inflammation and improve insulin resistance, steatosis and liver histology. ${ }^{23}$ There are currently no approved pharmacological therapies for NAFLD; oral vitamin $\mathrm{E}$ and pioglitazone are options that have shown modest clinical benefits.

\section{Epidemiologic Links Between Psoriasis and NAFLD}

The first published evidence in 2001 of a link between psoriasis and NAFLD involved three overweight/obese patients with NASH as confirmed by liver biopsy. ${ }^{24}$ Since then, various observational and controlled studies have highlighted an increased prevalence of NAFLD in patients with psoriasis. ${ }^{25-29}$ For example, in a large Dutch population-based study (2292 participants aged $\geq 55$ years) the prevalence of NAFLD was $46 \%$ in 118 patients with psoriasis and $33 \%$ in individuals without psoriasis. $^{27}$ Importantly, while elderly study participants with psoriasis were $70 \%$ more likely to have NAFLD than those without psoriasis (crude odds ratio [OR] 1.70, 95\% confidence interval [CI] 1.17-2.46), the increased risk was found to be independent of common risk factors such as smoking, alcohol consumption, and the presence of metabolic syndrome and its component disorders. A recent single-center cross-sectional study from Spain reported a 52\% prevalence of NAFLD among a cohort of 71 patients with psoriasis. $^{15}$ Of note, $14 \%$ of patients had liver fibrosis as diagnosed with transitional vibration-controlled elastography. A large population-based cohort study, using UK data from 197,130 patients with psoriasis and 1,279,754 matched controls, reported an elevated risk for incident cases of NAFLD among psoriasis patients without systemic therapy (adjusted hazard ratio [HR] 1.18, 95\% CI 1.07-1.30) and an even higher risk for those receiving systemic therapy (adjusted HR 2.23, 95\% CI 1.73-2.87) compared with the control group. ${ }^{30}$ The risk for incident NAFLD was also increased among patients with psoriatic arthritis, in particular for those receiving systemic therapy (adjusted HR 2.11, 95\% CI 1.55-2.87). In line with these results, a 2015 systematic review and meta-analysis including 7 case-control studies found that patients with psoriasis had a 2-fold increased risk of NAFLD compared with controls (6 studies; $n=267,761$; OR 2.15, 95\% CI 1.57-2.94). ${ }^{31}$ The risk of NAFLD was significantly greater in patients with psoriatic arthritis (3 studies; $\mathrm{n}=505$ patients; OR 2.25, 95\% CI 1.37-3.71) and in patients with severe psoriasis (2 studies; 51,930 patients, OR 2.07, 95\% CI 1.59-2.71) compared to those with mild psoriasis. Recently, this meta-analysis was updated to include 2 additional studies (for a total of $>3$ million 
patients and nearly 250,000 with NAFLD). ${ }^{32}$ The analysis was extended to investigate potential risk factors for NAFLD in psoriasis patients which included hypertension, male sex, hyperglycemia and obesity. Reaffirming the findings of the original systematic review, there was a strong association between psoriasis and NAFLD independent of confounders.

In several studies, the presence and severity of psoriasis were associated with a higher prevalence and greater severity of NAFLD, and NAFLD was a strong predictor of higher Psoriasis Area and Severity Index (PASI) scores. ${ }^{25,28,29,31,33}$ Using Control Attenuation Parameter to assess the degree of fatty liver and body surface area severity of psoriasis, Gandha et al confirmed a positive correlation between the two disorders. ${ }^{34}$ Furthermore, the progression to more severe forms of liver disease appeared to be higher in patients with psoriasis. ${ }^{35}$ Roberts et al reported that 48 of $103(47 \%)$ psoriasis patients had NAFLD and 23 of 103 (22\%) had biopsyconfirmed NASH, of whom $35 \%$ had stage $2-3$ fibrosis. ${ }^{35}$ The prevalence of NASH was markedly higher than the $12 \%$ previously reported in patients with similar demographic characteristics but without psoriasis in the same medical center. Moreover, concomitant NAFLD in patients with psoriasis may confer a higher 10-year cardiovascular risk compared to psoriasis patients without NAFLD. ${ }^{36}$

In summary, the epidemiologic association between NAFLD and psoriasis is particularly strong given the high prevalence and increased incidence observed among patients with psoriasis. Importantly, this association is more evident in patients with severe psoriasis compared with those with mild psoriasis and is independent of common traditional risk factors such as smoking, alcohol consumption, and the presence of metabolic syndrome and its component disorders. ${ }^{5,31,32}$

\section{Pathophysiological Links Between Psoriasis and NAFLD}

Psoriasis and NAFLD are amongst a number of multifactorial disorders (including cardiovascular diseases and metabolic syndrome) whose pathogenesis is not fully understood, but involves complex interactions between genetic, immunological and environmental factors (Figure 2). ${ }^{5,37-42}$

The pathophysiology of psoriasis is characterized by sustained, self-amplifying inflammatory responses that

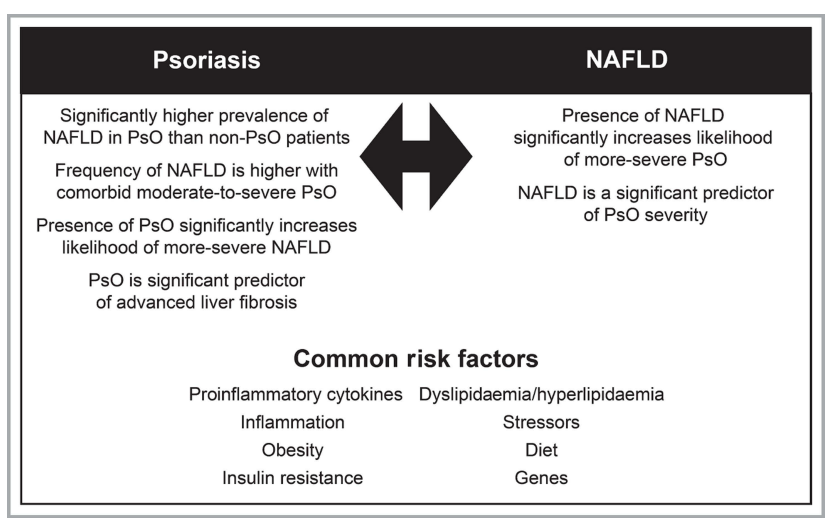

Figure 2 Common risk factors and associations between psoriasis ( $\mathrm{PsO}$ ) and nonalcoholic fatty liver disease (NAFLD). Reprinted from Prussick RB, Miele L. Nonalcoholic fatty liver disease in patients with psoriasis: a consequence of systemic inflammatory burden? Br J Dermatol. 2018;179(I):16-29. (c) 2018 The Authors. British Journal of Dermatology published by John Wiley \& Sons Ltd on behalf of British Association of Dermatologists. ${ }^{5}$

lead to uncontrolled keratinocyte proliferation and dysfunctional differentiation. Disturbances in both innate and adaptive cutaneous immune responses are responsible for psoriatic inflammation. ${ }^{43}$ Activation of the innate immune system driven by endogenous signals and cytokines coexists with an auto-inflammatory response in some patients and with $\mathrm{T}$ cell-driven auto-immune reactions in others. Thus, psoriasis exhibits traits of an auto-immune disease on an auto-inflammatory background, ${ }^{44,45}$ with both mechanisms overlapping and possibly potentiating one another. T helper (Th)-1, Th17 and Th22 cells and some of their associated pro-inflammatory cytokines, such as interleukin (IL)-17A and IL-22 and tumor necrosis factor alpha $(\mathrm{TNF}-\alpha)$ are critically involved in sustaining and maintaining psoriasis. ${ }^{45-48}$ The IL-23/IL-17 immune axis is considered to have a pivotal role in the pathogenesis of psoriasis; in line with this, IL-17- and IL-23-antagonists are highly effective treatments for psoriasis. ${ }^{49,50}$

The pathogenesis of NAFLD is complex and involves multiple pathways. Important pathophysiological mechanisms include genetic factors, insulin resistance and hyperinsulinemia, oxidative stress and hepatocyte lipotoxicity, hepatic inflammation, fibrosis, and gastrointestinal dysbiosis. $^{21,38,51-55}$ The various factors are encompassed in a "multiple hit" model for NAFLD development and progression. $^{21,56}$ In the early stages of NAFLD, insulin resistance - possibly related to an increase in pro-inflammatory cytokines - plays a pivotal role by increasing the release of circulating free fatty acids, followed by abnormal accumulation of triglycerides in liver cells and hepatic steatosis. This may be followed by a phase in which 
simple steatosis transitions into steatohepatitis as a result of an increased inflammatory response. Additional pathways subsequently involved in NAFLD progression include mitochondrial dysfunction and liver apoptosis, increased oxidative stress, activation of the profibrogenic transforming growth factor- $\beta$ (TGF- $\beta$ ) pathway, and hepatic stellate cell activation and injury. ${ }^{5}$

While the exact underlying mechanisms must still be fully clarified, both psoriasis and NAFLD are strongly associated with low-grade, chronic inflammation, peripheral insulin resistance, and increased levels of oxidative stress. $^{40,57}$ Elevated insulin resistance and increased release of inflammatory cytokines are also characteristic of the metabolic syndrome and obesity. Adipose tissue produces adipocytokines (or adipokines) such as adiponectin, leptin and resistin, as well as pro-inflammatory cytokines which play important roles in the pathogenesis of both psoriasis and NAFLD.

Besides the important role of adipose tissue in mediating the interplay between skin and liver, (severe) psoriasis may have a direct impact on NAFLD, possibly via mechanisms beyond overweight and obesity. Indeed, NAFLD in the general population can also occur among individuals who are not obese and have a normal body mass index. These individuals are labelled as "lean" NAFLD. ${ }^{58}$ Interestingly, compared to healthy subjects, individuals with "lean" NAFLD have higher mean serum C-reactive protein (CRP) levels, suggesting that systemic inflammation might be one of the pathogenic factors. $^{58}$

The secretion of pro-inflammatory cytokines from psoriatic tissue into the general circulation may reinforce the prevailing systemic pro-inflammatory milieu associated with NAFLD. IL-6, IL-17, TNF- $\alpha$ and CRP produced by the liver (hepatokines) and psoriatic skin have reciprocal direct effects on these organs (Figure 3 ). The pro-inflammatory effects of adipocytokines and hepatokines are summarized in Table 1. Importantly, there may be a bi-directional relationship between psoriasis and NAFLD through pro-inflammatory pathways, postulated as the hepato-dermal axis. ${ }^{48}$ Circulating pro-inflammatory cytokines such as TNF- $\alpha$ and IL-17 derived from psoriatic skin, upon reaching the liver, could impact liver inflammation and insulin resistance. Conversely, pro-inflammatory mediators stemming from hepatic inflammation could contribute to the onset or exacerbation of cutaneous inflammation in psoriasis. Pro-inflammatory immune modulators released by adipose tissue and the liver are involved in the

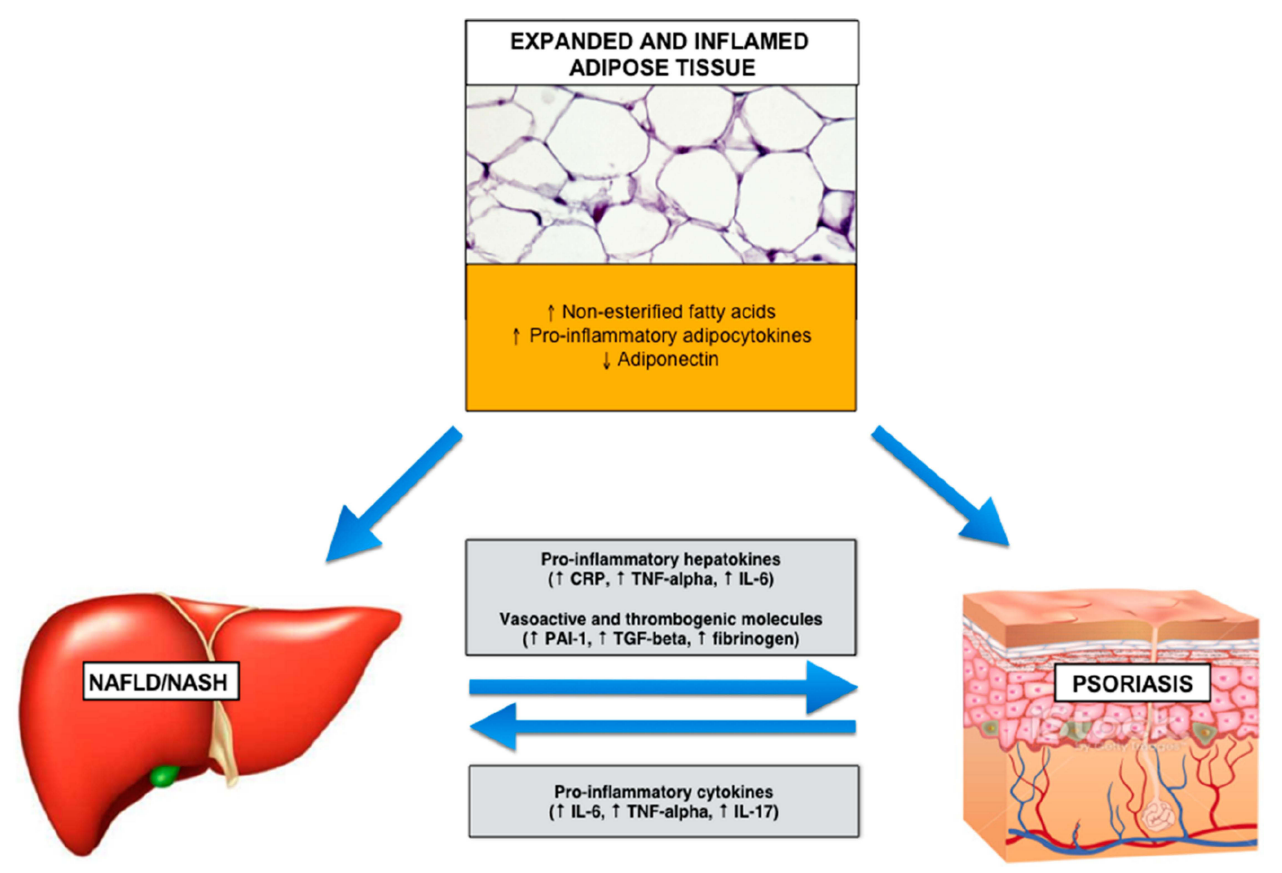

Figure 3 Possible mechanisms linking dysfunctional visceral adipose tissue, psoriatic skin and steatosis.

Notes: Reproduced from Mantovani A, Gisondi P, Lonardo A, et al. Relationship between non-alcoholic fatty liver disease and psoriasis: a novel hepato-dermal axis? Int J Mol Sci. 2016;17(2):217. ${ }^{48}$

Abbreviations: CRP, C-reactive protein; IL-6, interleukin-6; IL-I7, interleukin-I7; NAFLD, non-alcoholic fatty liver disease; NASH, non-alcoholic steatohepatitis; PAI-I, plasminogen activator inhibitor-I; TGF- $\beta$, transforming growth factor-beta; TNF- $\alpha$, tumor necrosis factor alpha. 
Table I Cytokine Levels and Effects of Adipocytokines and Hepatokines in Psoriasis and Non-Alcoholic Fatty Liver Disease (NAFLD)

\begin{tabular}{|c|c|c|}
\hline \multirow[t]{2}{*}{ Cytokine Level in Psoriasis and NAFLD } & \multicolumn{2}{|c|}{ Effect } \\
\hline & Psoriasis & NAFLD \\
\hline $\begin{array}{l}\text { Pro-inflammatory adipocytokines levels } \\
\text { ( } \uparrow \text {, increased; } \downarrow \text {, decreased) }\end{array}$ & \multicolumn{2}{|c|}{ Role ( $\uparrow$, increases activity; $\downarrow$, decreases activity) } \\
\hline TNF- $\alpha \uparrow$ & $\begin{array}{l}\uparrow \text { Keratinocyte proliferation, pro-inflammatory } \\
\text { cytokines, angiogenesis }\end{array}$ & $\begin{array}{l}\uparrow \text { Hepatic fibrogenesis: contributes to } \\
\text { insulin resistance }\end{array}$ \\
\hline IL-I $\uparrow$ & $\begin{array}{l}\uparrow \text { Keratinocyte proliferation, adhesion molecule } \\
\text { expression, pro-inflammatory cytokines }\end{array}$ & $\begin{array}{l}\text { Activation of mitogen-activated protein } \\
(M A P) \text { and ergosterol pathways }\end{array}$ \\
\hline $\mathrm{IL}-6 \uparrow$ & $\uparrow$ Keratinocyte proliferation & Contributes to insulin resistance \\
\hline Leptin $\uparrow$ & $\begin{array}{l}\uparrow \text { Keratinocyte proliferation, ThI response, } \\
\text { angiogenesis }\end{array}$ & $\begin{array}{l}\uparrow \text { Leptin resistance: contributes to hepatic } \\
\text { fibrogenesis }\end{array}$ \\
\hline Resistin $\uparrow$ & $\uparrow$ Pro-inflammatory cytokines & $\uparrow$ Insulin resistance \\
\hline Visfatin $\uparrow$ & & Contributes to insulin resistance \\
\hline Ghrelin $\uparrow$ & & Negatively correlated to TNF- $\alpha$ \\
\hline \multicolumn{3}{|l|}{ Anti-inflammatory adipocytokines } \\
\hline Adiponectin $\downarrow$ & $\downarrow$ Anti-inflammatory cytokines & $\downarrow$ Insulin sensitivity \\
\hline \multicolumn{3}{|l|}{ Pro-inflammatory hepatokines } \\
\hline Fibroblast growth factor $2 \mathrm{I}(\mathrm{FGF} 2 \mathrm{I}) \uparrow *$ & - & \\
\hline \multicolumn{3}{|l|}{ Fetuin $\mathrm{A} \uparrow$} \\
\hline $\mathrm{CRP} \uparrow$ & & $\uparrow$ Hepatic fibrogenesis \\
\hline \multicolumn{3}{|l|}{ TNF- $\alpha \uparrow$} \\
\hline $\mathrm{IL}-6 \uparrow$ & & $\uparrow$ Hepatic fibrogenesis \\
\hline
\end{tabular}

Notes: *NAFLD only. $\uparrow$, elevated, $\downarrow$ de-elevated. Adapted from Prussick RB, Miele L. Non-alcoholic fatty liver disease in patients with psoriasis: a consequence of systemic inflammatory burden? Br J Dermatol. 2018;179(I):16-29. @ 2018 The Authors. British Journal of Dermatology published by John Wiley \& Sons Ltd on behalf of British Association of Dermatologists. ${ }^{5}$

Abbreviations: CRP, C-reactive protein; IL, interleukin; TNF- $\alpha$, tumour-necrosis factor alpha.

promotion of hepatic fibrogenesis in NAFLD as well as psoriasis pathogenesis. ${ }^{5,40,48,59}$ TNF- $\alpha$, for example, is involved in psoriasis inflammation and has been shown to be an independent predictor of hepatic fibrogenesis and disease progression. ${ }^{60}$ Another relevant cytokine in this context is IL-17, which plays a central role in psoriasis pathogenesis. IL-17 is able to induce hepatic stellate cells activation and subsequent collagen production. ${ }^{50,61} \mathrm{By}$ doing so, IL-17 facilitates the progression from simple liver steatosis to steatohepatitis. ${ }^{50,61,62}$

High circulating (or hepatic) levels of proprotein convertase subtilisin kexin type-9 (PCSK9) have been shown to play a key role in muscle and liver lipid storage, adipose energy storage and hepatic fatty acids and triglycerides storage and secretion. These effects contribute to involvement of the enzyme in the pathogenesis of both NAFLD $^{63}$ and psoriasis. ${ }^{64}$

Other shared pathways between psoriasis and NAFLD include modulation of lipid and glucose metabolism, which both play an important role in the development of metabolic syndrome and keratinocyte proliferation in psoriasis.

In summary, there is significant overlap in the pathophysiological factors underlying psoriasis and NAFLD, mostly relating to pathways involving inflammation, oxidative stress, and glucose and lipid metabolism.

\section{Hepatic Effects of Systemic Psoriasis Treatments}

Given the strong pathophysiological links between psoriasis and NAFLD and the high prevalence of NAFLD 
among psoriasis patients, dermatologists should always screen for possible liver disease in their psoriasis patients. A good understanding of the potential hepatic effects of systemic treatments prescribed for patients with psoriasis would also be clinically important. NAFLD-promoting drugs should be avoided, especially in high-risk patients. On the other hand, systemic therapies that reduce systemic inflammation may have a positive influence and mitigate the risk of developing NAFLD. Below, we summarize hepatotoxic and potential hepatoprotective effects of currently approved systemic psoriasis therapies with a focus on NAFLD.

\section{Hepatotoxic Effects of Systemic Psoriasis Treatment}

Hepatotoxic risk is associated with the administration of a number of conventional drugs used in the treatment of psoriasis. Evidence for currently approved systemic psoriasis treatments is presented in Table $2 .{ }^{65-87}$ Patients prescribed these medications should be monitored carefully for hepatotoxicity.

Perhaps the most substantive evidence, and concern, regarding potential hepatotoxicity relates to methotrexate. $^{65-70}$ Early signs of negative effects of methotrexate on liver function include elevated hepatic

Table 2 Potential Hepatotoxic Effects of Some of the Most Commonly Used Systemic Therapies Used in the Treatment of Moderate to Severe Psoriasis

\begin{tabular}{|c|c|c|c|}
\hline $\begin{array}{l}\text { Systemic } \\
\text { Antipsoriatic } \\
\text { Agent }\end{array}$ & $\begin{array}{l}\text { Pharmacological } \\
\text { Class }\end{array}$ & Potential Hepatotoxic Effects & Likely Causality $^{\mathbf{a}}$ \\
\hline \multicolumn{4}{|c|}{ Non-biological agents } \\
\hline Acitretin (ACl) & Retinoid & $\begin{array}{l}\text { Transient } \uparrow A M T \text { levels in up to } 30 \% \text { pts; rare acute toxic } \\
\text { hepatitis; uncommon acute liver injury has been reported }\end{array}$ & $\begin{array}{l}\mathrm{ACl} \text { is a probable cause of clinically } \\
\text { apparent liver injury }\end{array}$ \\
\hline $\begin{array}{l}\text { Apremilast } \\
\text { (APR) }\end{array}$ & PD-4 inhibitor & No reported hepatotoxicity & $\begin{array}{l}\text { APR is an unlikely cause of apparent liver } \\
\text { injury, but clinical experience is limited }\end{array}$ \\
\hline $\begin{array}{l}\text { Cyclosporin } \\
(\mathrm{CYC})\end{array}$ & $\begin{array}{l}\text { Calcineurin } \\
\text { inhibitor }\end{array}$ & $\begin{array}{l}\text { Mild } \uparrow \text { in bilirubin and less commonly AMT levels; case } \\
\text { reports of acute liver injury have been reported }\end{array}$ & $\begin{array}{l}\text { CYC is a probable rare cause of clinically } \\
\text { apparent liver injury }\end{array}$ \\
\hline $\begin{array}{l}\text { Dimethyl } \\
\text { fumarate } \\
\text { (DMF) }\end{array}$ & $\begin{array}{l}\text { Immunomodulator } \\
\text { and anti- } \\
\text { inflammatory }\end{array}$ & $\begin{array}{l}\uparrow A M T \text { levels which were asymptomatic and transient; } \\
\text { isolated cases of clinically apparent liver injury with jaundice } \\
\text { have been reported during widescale use of DMF }\end{array}$ & $\begin{array}{l}\text { DMF is a probable rare cause of clinically } \\
\text { apparent liver injury }\end{array}$ \\
\hline $\begin{array}{l}\text { Methotrexate } \\
\text { (MTX) }\end{array}$ & Folic acid antagonist & $\begin{array}{l}\text { During long-term low-dose MTX treatment } \uparrow \text { AMT levels; } \\
\text { NAFLD, liver fibrosis and cirrhosis; with higher doses of } \\
\text { MTX the increases in AMT levels are greater }\end{array}$ & $\begin{array}{l}\text { MTX is a well-known cause of clinically } \\
\text { significant hepatic injury, portal } \\
\text { hypertension and cirrhosis }\end{array}$ \\
\hline \multicolumn{4}{|c|}{ Biological agents } \\
\hline $\begin{array}{l}\text { Adalimumab } \\
\text { (ADA) }\end{array}$ & Anti-TNF $\alpha$ & $\begin{array}{l}\text { Low risk of transient, mild, asymptomatic } \uparrow \text { AMT levels; acute } \\
\text { DILI (including AIH); cholestasis; reactivation of hepatitis B }\end{array}$ & $\begin{array}{l}\text { ADA is a likely cause of clinically } \\
\text { apparent liver injury }\end{array}$ \\
\hline $\begin{array}{l}\text { Certolizumab } \\
\text { (CER) }\end{array}$ & Anti-TNF $\alpha$ & $\begin{array}{l}\text { Low risk of transient, mild, asymptomatic } \uparrow \text { AMT levels; acute } \\
\text { DILI (including AIH); cholestasis; reactivation of hepatitis B }\end{array}$ & $\begin{array}{l}\text { CER is an unproven but suspected cause } \\
\text { of apparent liver injury }\end{array}$ \\
\hline $\begin{array}{l}\text { Etanercept } \\
\text { (ETA) }\end{array}$ & Anti-TNF $\alpha$ & $\begin{array}{l}\text { Low risk of transient, mild, asymptomatic } \uparrow A M T \text { levels; acute } \\
\text { DILI (including AlH), but much less than INF; cholestasis; } \\
\text { reactivation of hepatitis B }\end{array}$ & $\begin{array}{l}\text { ETA is a highly likely cause of clinically } \\
\text { apparent liver injury }\end{array}$ \\
\hline Infliximab (INF) & Anti-TNF $\alpha$ & $\begin{array}{l}\text { Risk of transient, mild, asymptomatic } \uparrow A M T \text { levels, but } \\
\text { sometimes the } \uparrow \text { continues to progress; } \uparrow \text { ALP; symptomatic } \\
\text { hepatitis; acute DILI (including AIH); cholestasis; reactivation } \\
\text { of hepatitis B }\end{array}$ & $\begin{array}{l}\text { INF is a highly likely cause of clinically } \\
\text { apparent liver injury }\end{array}$ \\
\hline
\end{tabular}

(Continued) 
Table 2 (Continued).

\begin{tabular}{|c|c|c|c|}
\hline $\begin{array}{l}\text { Systemic } \\
\text { Antipsoriatic } \\
\text { Agent }\end{array}$ & $\begin{array}{l}\text { Pharmacological } \\
\text { Class }\end{array}$ & Potential Hepatotoxic Effects & Likely Causality $^{\mathrm{a}}$ \\
\hline $\begin{array}{l}\text { Ustekinumab } \\
\text { (UST) }\end{array}$ & $\begin{array}{l}\text { Anti-ILI } 2 \text { and anti- } \\
\text { IL23 }\end{array}$ & $\begin{array}{l}\text { No evidence of liver enzyme anomalies or reports of liver } \\
\text { injury with UST to date. Rare instances of reactivation of } \\
\text { hepatitis B have been reported. Experience with UST is limited }\end{array}$ & $\begin{array}{l}\text { UST is an unproven but suspected rare } \\
\text { cause of apparent liver injury and } \\
\text { reactivation of hepatitis B }\end{array}$ \\
\hline $\begin{array}{l}\text { Brodalumab } \\
(\text { BRO) }\end{array}$ & Anti-ILI7 & $\begin{array}{l}\text { No evidence of liver enzyme anomalies or reports of liver } \\
\text { injury with BRO to date. Experience with BRO is limited }\end{array}$ & $\begin{array}{l}\text { BRO is an unlikely cause of apparent liver } \\
\text { injury }\end{array}$ \\
\hline $\begin{array}{l}\text { Ixekizumab } \\
\text { (IXE) }\end{array}$ & Anti-ILI7 & $\begin{array}{l}\text { No evidence of liver enzyme anomalies or reports of liver } \\
\text { injury with IXE to date. Experience with IXE is limited }\end{array}$ & $\begin{array}{l}\text { IXE is an unlikely cause of clinically } \\
\text { apparent liver injury }\end{array}$ \\
\hline $\begin{array}{l}\text { Secukinumab } \\
\text { (SEC) }\end{array}$ & Anti-ILI7 & $\begin{array}{l}\text { No evidence of liver enzyme anomalies or reports of liver } \\
\text { injury with SEC to date }\end{array}$ & $\begin{array}{l}\text { SEC is an unlikely cause of apparent liver } \\
\text { injury }\end{array}$ \\
\hline $\begin{array}{l}\text { Guselkumab } \\
\text { (GUS) }\end{array}$ & Ant-IL23 & $\begin{array}{l}\text { Mild-to-moderate } \uparrow A M T \text { levels which resolved even if } \\
\text { treatment with GUS was continued. No evidence of acute } \\
\text { liver injury, or reactivation of hepatitis B or worsening of } \\
\text { hepatitis C with GUS to date, but clinical experience is } \\
\text { limited }\end{array}$ & $\begin{array}{l}\text { GUS is an unproven but suspected rare } \\
\text { cause of apparent liver injury }\end{array}$ \\
\hline $\begin{array}{l}\text { Risankizumab } \\
\text { (RIS) }\end{array}$ & Anti-IL23 & $\begin{array}{l}\text { Risankizumab has been associated with a low rate of serum } \\
\text { aminotransferase elevations during therapy, but has not been } \\
\text { linked to instances of clinically apparent liver injury. }\end{array}$ & $\begin{array}{l}\text { RIS is an unlikely cause of apparent liver } \\
\text { injury }\end{array}$ \\
\hline $\begin{array}{l}\text { Tildrakizumab } \\
\text { (TIL) }\end{array}$ & Anti-IL23 & $\begin{array}{l}\text { No evidence of liver enzyme anomalies or reports of liver } \\
\text { injury, or reactivation of hepatitis B or worsening of hepatitis } \\
\text { C with TIL to date, but clinical experience is limited }\end{array}$ & $\begin{array}{l}\text { TIL is an unlikely cause of apparent liver } \\
\text { injury }\end{array}$ \\
\hline
\end{tabular}

Notes: a Based on LiverTox ratings. ${ }^{76}$ Data from these studies. ${ }^{65-87}$

Abbreviations: $\uparrow$, elevated; AlH, autoimmune hepatitis; ALP, serum alkaline phosphatase; AMT, aminotransferase; DILI, drug induced liver injury; IL, interleukin; NAFLD, non-alcoholic fatty liver disease; TNF, tumor necrosis factor.

transaminase levels, but of even greater concern are methotrexate-induced histological changes including aggravation of underlying fatty liver to NAFLD and steatohepatitis with possible fibrosis and cirrhosis. ${ }^{71,72}$ These more serious adverse hepatic effects have been reported to occur in about $5 \%$ of patients treated with chronic, low-dose methotrexate, although rarely in patients without additional clinical risk factors for hepatotoxicity, such as pre-existing liver disease, excessive alcohol abuse, hepatitis B or C, central obesity and type 2 diabetes. $^{71}$ Given the hepatotoxic concerns, use of methotrexate is preferably avoided in these high-risk psoriasis patient groups, including those with established NAFLD, and methotrexate is contraindicated if bilirubin values are $>5 \mathrm{mg} / \mathrm{dl}^{73}$

Cyclosporin may cause dose-dependent, reversible increases in serum bilirubin and liver enzymes, with post-marketing experience reporting hepatotoxicity and liver injury. ${ }^{65,68,74}$ Cyclosporin can also potentially worsen
NAFLD by increasing serum lipid levels. ${ }^{75}$ Close monitoring of liver function test enzymes and lipid parameters is recommended as abnormal values may necessitate dose reductions. ${ }^{68,74,76}$ Another frequently occurring adverse event associated with cyclosporin use is hypertension, which would be expected to negatively impact NAFLD.

Cases of liver enzyme increases $(\geq 3$ upper limit of normal [ULN]) and elevation of total bilirubin levels ( $\geq 2$ ULN) have been reported infrequently for dimethyl fumarate (DMF), with resolution after treatment discontinuation. Assessment of serum aminotransferases (eg, alanine aminotransferase [ALT], aspartate aminotransferase [AST]) and total bilirubin levels are recommended prior to treatment initiation and during treatment. ${ }^{68,77} \mathrm{DMF}$ is considered to be a possible rare cause of liver toxicity. ${ }^{78}$

Acitretin has been associated with transient increases in liver enzymes, but hepatotoxicity has been reported rarely. ${ }^{65}$ As acitretin frequently causes hyperlipidemia, use is preferably avoided in patients with or at high risk of NAFLD. ${ }^{11,75,79,80}$ 
No hepatotoxic effects have been documented for apremilast $^{65}$ and no routine laboratory monitoring is required. Apremilast is considered to be an unlikely cause of apparent liver injury. ${ }^{78}$

There is evidence of hepatotoxic risk with TNF- $\alpha$ inhibitors such as infliximab, adalimumab, certolizumab and etanercept $\mathrm{t}^{65,81-83}$ and guidelines advocate monitoring liver enzymes during treatment. ${ }^{65}$ Furthermore, compared with conventional systemic therapies for psoriasis (methotrexate and cyclosporin), treatment with TNF inhibitors (adalimumab, infliximab and etanercept) was found to be associated with significant increases in bodyweight and body mass index in a network meta-analysis (6 studies and 862 psoriasis patients) ${ }^{84}$ Increases in body weight might be associated with a reduction in the therapeutic response and/or exacerbations of comorbidities, although this needs to be confirmed in prospective studies. TNF inhibitors should be used cautiously in patients with or at high risk of NAFLD.

Other biologicals such as anti-IL17 agents (brodalumab, ixekizumab and secukinumab) and ustekinumab (anti-IL12/23) have been less widely investigated, but have generally exhibited minimal hepatotoxicity (Table 2). A retrospective study of 44 psoriasis patients receiving ustekinumab identified 6 cases (13.6\%) of mild elevated transaminases, with no cases of severe hypertransaminasemia. ${ }^{85}$ Overall, the reported rate of mild-to-moderate serum aminotransferase elevations following ustekinumab therapy was $0.5 \%$ to $1.4 \%$. There have been no reports of treatment-related symptomatic acute liver injury or jaundice linked to ustekinumab therapy ${ }^{78}$ Interestingly, limited data found no increases in bodyweight in patients treated with ustekinumab. ${ }^{84,88}$

Analysis of over 3000 patients in clinical trials of the IL-17 antagonist secukinumab in psoriasis showed low rates of serum liver enzyme elevations compared to placebo and no cases of treatment-related liver injury. Postmarketing data have revealed no reports of liver injury due to secukinumab therapy. ${ }^{78}$ Similarly, clinical trials $(>3000$ patients) and post-marketing studies of the anti-IL-17 biologic brodalumab have shown no evidence of liver enzyme elevation nor liver injury attributable to the agent. ${ }^{78}$ Comparable rates of serum liver enzyme elevations with the IL-17 antagonist ixekizumab and placebo were found in clinical trials, with no treatment-related cases of liver injury. Although post-marketing approval experience with ixekizumab is relatively limited, no cases of treatmentrelated liver injury have been reported. ${ }^{78}$ For newer anti-
IL-23 biologics recently approved for the treatment of psoriasis (eg, guselkumab, risankizumab, and tildrakizumab), no evidence of acute liver injury or reactivation of hepatitis $\mathrm{B}$ or worsening of hepatitis $\mathrm{C}$ has been reported to date, but clinical experience with these agents is very limited (Table 2).

\section{Hepatoprotective Effects of Systemic Psoriasis Treatment}

Assessment of hepatoprotection can be derived from several different research pathways including in vitro experiments, animal models and monitoring of potential biomarkers (Table 3) ${ }^{89-108}$ Given the common etiology of inflammation between psoriasis and NAFLD, it might be postulated that systemic therapies for psoriasis that attenuate systemic inflammation may also have beneficial effects on NAFLD by targeting pro-inflammatory cytokines. ${ }^{109}$ However, to date, clinical data are scarce for any direct hepatoprotective effects of systemic psoriasis treatments.

\section{Methotrexate}

Methotrexate has exhibited beneficial effects on cardiovascular inflammation ${ }^{91,92}$ as well as decreasing serum levels of PCSK9, which is a likely marker of improved lipid metabolism (Table 3). ${ }^{89}$ However, a large placebo-controlled RCT failed to show any benefits of methotrexate on the risk of cardiovascular events. ${ }^{110}$ Furthermore, the potential hepatotoxic risks associated with methotrexate therapy, as discussed earlier, would generally preclude its use in patients with NAFLD.

\section{Acitretin}

From the clinical study of Krahel et al, ${ }^{89}$ acitretin treatment was shown to increase PCSK9 levels, but there was no correlation between these elevated levels and markers of liver function such as transaminases in hepatic steatosis and NASH in high-risk patients (Table 3). Fibroblast growth factors (FGFs) 21 and 23 are markers for cardiometabolic disorders which are common in psoriasis. In one small trial, acitretin was reported to decrease FGF-21 by three-fold which was significantly greater than the reduction observed with methotrexate. ${ }^{90}$ In an earlier small clinical trial, it was shown that patients with chronic psoriasis treated with acitretin had reduced retinol-binding protein-4 levels and decreased insulin resistance. ${ }^{111}$ Given the link between psoriasis and increased insulin resistance/ 
Table 3 Potential Hepatoprotective Effects of Medicines Used to Treat Psoriasis

\begin{tabular}{|c|c|c|}
\hline Treatment and Assessment & Results and Conclusions & Ref. \\
\hline \multicolumn{3}{|l|}{ Effects on inflammatory biomarkers: non-biological agents } \\
\hline $\begin{array}{l}\text { MTX and ACI } \\
\text { PCSK9 plays a role in maintaining lipid homeostasis by binding to } \\
\text { LDL-R and is considered a cardiometabolic risk factor. Effects of } \\
\text { MTX and ACl on PCSK9 levels in PSO pts and healthy volunteers } \\
\text { after } 12 \text { weeks' treatment }\end{array}$ & $\begin{array}{l}\text { PSO pts had significantly elevated PCSK9 levels compared with } \\
\text { controls and these were positively correlated to BMI and TG } \\
\text { levels. MTX, but not ACl, significantly reduced PCSK9 levels. } \\
\text { However, there was no correlation between PCSK9 levels and } \\
\text { markers of liver function such as transaminases in hepatic steatosis } \\
\text { and NASH in high-risk patients }\end{array}$ & [89] \\
\hline $\begin{array}{l}\text { MTX and ACI } \\
\text { FGFs } 2 I \text { and } 23 \text { are markers for cardiometabolic disorders which } \\
\text { are common in PSO. Effects of MTX and ACl on FGF-2I and }-23 \\
\text { in PSO pts and healthy controls after } 12 \text { weeks' treatment }\end{array}$ & $\begin{array}{l}\text { FGF-2I levels were increased in PSO pts vs controls whereas FGF- } 23 \\
\text { levels were not. There was a tendency for higher levels of FGF- } 2 \text { I in } \\
\text { pts with more severe PSO which raises the possibility of its use as a } \\
\text { biomarker for disease severity. Interestingly, ACl decreased FGF-2I } \\
\text { more than MTX. Finally, there was a positive link between FGF-23 and } \\
\text { AST levels which suggests a possible link with liver activity }\end{array}$ & {$[90]$} \\
\hline $\begin{array}{l}\text { MTX } \\
\text { Review of the evidence for the potential pro-atherosclerotic } \\
\text { effects of MTX }\end{array}$ & $\begin{array}{l}\text { MTX improves endothelial function and vascular homeostasis, and } \\
\text { is associated with a significant reduction in CV morbidity. These } \\
\text { effects appear to be mediated via inhibition of pro-atherosclerotic } \\
\text { cytokines such as TNF- } \alpha \text {, IL-I and IL- } 6\end{array}$ & {$[91,92]$} \\
\hline $\begin{array}{l}\text { CYC } \\
\text { TGF } \beta \text { s plays a key role in cell growth and differentiation, modulation } \\
\text { of immune activity and regulation of the cell cycle. The effects of CYC } \\
\text { on TGF } \beta \text { levels was determined in PSO pts treated for } 12 \text { weeks }\end{array}$ & $\begin{array}{l}\text { CYC significantly improved PSO symptoms and QoL of pts in this } \\
\text { 3-month clinical study. CYC also increased the transcription } \\
\text { activity of TGF } \beta \text { I at the end of treatment in pts with or without } \\
\text { diabetes, and with or without metabolic syndrome }\end{array}$ & [93] \\
\hline $\begin{array}{l}\text { APR } \\
\text { Assessment of efficacy, safety and metabolic biomarkers in II } 3 \text { pts } \\
\text { with PSO and/or PsA treated with APR for I-year }\end{array}$ & $\begin{array}{l}\text { Pts with diabetes treated with APR achieved better clinical benefit } \\
\text { for their PSO (extent and severity) compared with non-diabetic } \\
\text { patients. In addition, after I year, blood glucose levels and LDL-C } \\
\text { levels were significantly reduced by APR }\end{array}$ & [94] \\
\hline \multicolumn{3}{|l|}{ Effects on inflammatory biomarkers: biological agents } \\
\hline $\begin{array}{l}\text { ADA } \\
\text { A I 2-week RCT comparing the effects of ADA, PHO and PLA on } \\
\text { vascular inflammation and markers of lipid and glucose metabolism, } \\
\text { and inflammation in pts with moderate to severe PSO. This was } \\
\text { followed by } 52 \text {-week open-label ADA }\end{array}$ & $\begin{array}{l}\text { ADA (anti-TNF) reduced key markers of inflammation including } \\
\text { glycoprotein acetylation, CRP, IL-6 and TNF whereas PHO only } \\
\text { reduced CRP and IL-6 }\end{array}$ & [95] \\
\hline $\begin{array}{l}\text { ADA and FAEs } \\
\text { The effect of ADA and FAEs on CV disease markers in pts with } \\
\text { PSO was investigated in a } 6 \text {-month RCT }\end{array}$ & $\begin{array}{l}\text { ADA and FAEs were associated with beneficial CV effects. ADA } \\
\text { significantly reduced systemic inflammation as measured by CRP } \\
\text { levels and improved endothelial dysfunction as measured by flow- } \\
\text { mediated dilation. In contrast, FAEs significantly reduced total } \\
\text { cholesterol, LDL and apolipoprotein B levels }\end{array}$ & [96] \\
\hline $\begin{array}{l}\text { SEC } \\
\text { A I } 2 \text {-week RCT comparing the effects of SEC and PLA on markers } \\
\text { of inflammation, and lipid and glucose metabolism in pts with } \\
\text { moderate to severe PSO. This was followed by } 40 \text {-week open-label } \\
\text { SEC }\end{array}$ & $\begin{array}{l}\text { SEC (anti-IL-I7A) was highly effective for treating PSO, but had a } \\
\text { neutral effect on aortic vascular inflammation and biomarkers of } \\
\text { cardiometabolic disease }\end{array}$ & [97] \\
\hline $\begin{array}{l}\text { SEC } \\
\text { A post hoc analysis of } 3 \text { Phase III RCTs in pts with plaque PSO } \\
\text { comparing SEC with PLA (and ETA in one study) with regards } \\
\text { metabolic and liver parameters over } 12 \text { months }\end{array}$ & $\begin{array}{l}\text { Overall, SEC had neutral effects on fasting plasma glucose, lipid } \\
\text { parameters and liver enzymes. SEC reduced levels of CRP, a } \\
\text { marker for systemic inflammation }\end{array}$ & [98] \\
\hline
\end{tabular}


Table 3 (Continued).

\begin{tabular}{|c|c|c|}
\hline Treatment and Assessment & Results and Conclusions & Ref. \\
\hline $\begin{array}{l}\text { SEC or IXE (anti-IL-I7A therapy) } \\
\text { Determination of glucose levels in PSO pts to see if the severity of } \\
\text { PSO was correlated with hyperglycemia, and to investigate the } \\
\text { effects of anti-IL-I7A therapy on glucose levels }\end{array}$ & $\begin{array}{l}\text { In pts with PSO, the severity of the skin disease correlated with high } \\
\text { blood glucose levels. Anti-IL-I7A therapy significantly reduced } \\
\text { glycemia in patients with PSO. In parallel experiments it had the same } \\
\text { effect in imiquimod-treated mice (an animal model of psoriasis) }\end{array}$ & [99] \\
\hline $\begin{array}{l}\text { SEC } \\
\text { The effects of SEC, CYC, and MTX on myocardial deformation and } \\
\text { vascular function in PSO pts after 4- and 12-month treatment }\end{array}$ & $\begin{array}{l}\text { In patients with psoriasis, inhibition of IL- I7A with SEC produced } \\
\text { greater improvement in arterial elasticity, coronary artery function } \\
\text { and indices of myocardial deformation than either CYC or MTX. SEC } \\
\text { was also associated with a reduction in markers for oxidative stress }\end{array}$ & {$[100]$} \\
\hline $\begin{array}{l}\text { UST } \\
\text { A I2-week RCT comparing the effects of UST and PLA on markers } \\
\text { of inflammation, and lipid and glucose metabolism in pts with } \\
\text { moderate to severe PSO. This was followed by } 40 \text {-week open-label } \\
\text { UST }\end{array}$ & $\begin{array}{l}\text { UST (anti-IL-I } 2 \text { and -IL-23) was highly effective for treating PSO } \\
\text { and was associated with a reduction in IL- I7a levels (a key cytokine } \\
\text { in PSO). At the end of the study UST significantly decreased TNF- } \\
\alpha \text {, IL-Ib, IL-I Ia and IL-6. VCAM-I was significantly reduced by UST } \\
\text { at I } 2 \text { weeks, but this was not sustained at } 52 \text { weeks. Overall, UST } \\
\text { transiently reduced aortic vascular inflammation at I } 2 \text { weeks. } \\
\text { Longer term UST produced a more durable reduction in markers } \\
\text { (inflammatory cytokines) associated with CV disease }\end{array}$ & {$[101]$} \\
\hline \multicolumn{3}{|l|}{ Effects in vitro } \\
\hline $\begin{array}{l}\text { Effect of DMF/MEF on GM-CSF- and IL-4-induced differentiation of } \\
\text { monocyte derived DCs } \\
\text { In vitro using human cell line }\end{array}$ & $\begin{array}{l}\text { DMF concentration-dependently inhibited monocyte-derived DC } \\
\text { differentiation as reflected by inhibition of CDIa, CD } 40, C D 80 \text {, } \\
\text { CD86 and HLA-DR, and reduced capacity to stimulate } \\
\text { lymphocytes. This suggests that the mechanism of action of DMF/ } \\
\text { MEF in psoriasis is possibly based on immunomodulatory effects } \\
\text { mediated through inhibition of DCs }\end{array}$ & [102] \\
\hline $\begin{array}{l}\text { Effect of DMF on DC maturation and subsequent T-cell responses } \\
\text { In vitro using mouse cell line }\end{array}$ & $\begin{array}{l}\text { DMF inhibited DC maturation by reducing inflammatory IL-I } 2 \text { and } \\
\text { IL-6 production as well as expression of MHC class II, CD } 80 \text { and } \\
\text { CD86. This immature DC phenotype resulted in fewer activated } \\
\text { T-cells (and decreased IFN- } \gamma \text { and IL-I7 production). DMF } \\
\text { modulates inflammation by inhibiting DC maturation and } \\
\text { subsequent ThI and ThI7 cell differentiation }\end{array}$ & [103] \\
\hline \multicolumn{3}{|c|}{ Animal models investigating possible hepatoprotective effects of systemic antipsoriatic medications } \\
\hline $\begin{array}{l}\text { To evaluate the antioxidant and anti-inflammatory effects of DMF } \\
\text { as mechanisms for ameliorating liver toxicity } \\
\text { Rat model of liver ischemia/ reperfusion injury }\end{array}$ & $\begin{array}{l}\text { Liver histological tissue damage was significantly reduced by DMF and } \\
\text { this was associated with lower ALT and MDA levels. In addition, DMF } \\
\text { was associated with higher expression of anti-oxidant enzymes } \\
\text { (catalase and glutamate-cysteine ligase modifier subunit) and lower } \\
\text { levels of inflammatory mediators (nuclear factor-kappa B and cyclo- } \\
\text { oxygenase-2). In a rat model of liver ischemia /injury, DMF significantly } \\
\text { improved hepatic function and the anti-oxidant and inflammation } \\
\text { status compared with controls (no treatment) }\end{array}$ & [104] \\
\hline $\begin{array}{l}\text { Effects on aerobic glycolysis in the modulation of immunity } \\
\text { In vitro and in vivo experiments in mice and humans }\end{array}$ & $\begin{array}{l}\text { DMF, an immunomodulatory drug, inactivated the catalytic cysteine } \\
\text { of GAPDH involved in aerobic glycolysis in activated myeloid and } \\
\text { lymphoid cells. Importantly DMF differentially impacted } \\
\text { lymphocyte subsets, producing lymphopenia that selectively } \\
\text { depleted highly glycolytic effector T-cells while sparing oxidative } \\
\text { naïve T-cells and Treg cells. The anti-inflammatory/ } \\
\text { immunomodulatory effects of DMF may be mediated via inhibition } \\
\text { of GAPDH and aerobic glycolysis }\end{array}$ & [105] \\
\hline
\end{tabular}


Table 3 (Continued).

\begin{tabular}{|c|c|c|}
\hline Treatment and Assessment & Results and Conclusions & Ref. \\
\hline $\begin{array}{l}\text { T-cell response to DMF } \\
\text { Mouse model of EAE }\end{array}$ & $\begin{array}{l}\mathrm{PLP}_{139-151} \text { peptide-reactive DMF-treated IL- } 17^{\text {low }} \text {, IFN- } \gamma^{\text {low }}, \mathrm{IL}-4^{+} \\
\mathrm{CD} 4^{+} \mathrm{T} \text {-cells may protect mice from severe EAE. DMF-induced IL- } \\
\mathrm{I} 7^{\text {low }}, \mathrm{IFN}-\gamma^{\text {low }}, \mathrm{IL}-4^{+} \text {Th cells protect mice from severe EAE }\end{array}$ & {$[106]$} \\
\hline $\begin{array}{l}\text { Effect of DMF on hepatic injury } \\
\text { Mouse model of ACT-induced hepatic injury }\end{array}$ & $\begin{array}{l}\text { In this model DMF ameliorated ACT-induced liver injury primarily } \\
\text { through anti-oxidant, anti-inflammatory and anti-apoptotic } \\
\text { mechanisms in a Nrf-2-dependent manner. These results show that } \\
\text { DMF can possibly be used for treating ACT-induced liver damage } \\
\text { through targeting the Nrf-2/HO-I pathway }\end{array}$ & {$[107]$} \\
\hline $\begin{array}{l}\text { Effect of DMF on hepatic injury } \\
\text { Rat model of TAA-induced hepatic injury }\end{array}$ & $\begin{array}{l}\text { DMF restored TAA-induced increased levels of ALT, AST, GGT, } \\
\text { total bilirubin, uric acid, MDA, reduced glutathione. DMF also } \\
\text { improved histopathological findings such as inflammatory cell } \\
\text { infiltration, necrosis and bridging fibrosis. Markers of inflammation } \\
\text { and oxidative stress were also significantly improved by DMF. DMF } \\
\text { protects against TAA-induced hepatic damage via down-regulation } \\
\text { of the inflammatory cascade and up-regulation of anti-oxidant } \\
\text { mechanisms }\end{array}$ & {$[108]$} \\
\hline
\end{tabular}

Abbreviations: ACl, Acitretin; ACT, acetaminophen; ADA, adalimumab; ALT, alanine aminotransferase; AST, aspartate aminotransferase; CRP, C-reactive protein; DC, dendritic cells; DMF, dimethyl fumarate; EAE, experimental autoimmune encephalomyelitis; ETA, etanercept; FAEs, fumaric acid esters; FGF, fibroblast growth factors; GAPDH, glyceraldehyde 3-phosphate dehydrogenase; GGT, $\gamma$-glutamyl transferase; GM-CSF, granulocyte-macrophage-colony stimulating factor; HO-I, heme oxygenase-I; IL, interleukin; IXE, ixekizumab; LDL-R, low-density lipoprotein-receptor; MDA, malondialdehyde; MEF, monoethyl fumarate; MTX, methotrexate; Nrf-2/HO-I, nuclear factor erythroid-related factor-2; PHO, phototherapy; PLP, proteolipid protein; PCSK9, proprotein convertase subtilisin/kexin type 9; PSO, psoriasis; pts, patients; TAA, thioacetamide; TG, triglyceride.

diabetes these changes could be clinically meaningful if confirmed in a larger study. ${ }^{111}$

\section{Cyclosporin}

There is a paucity of data on the potential hepatoprotective effects of cyclosporin. In a small group of patients with moderate to severe psoriasis, comorbidity with diabetes or metabolic syndrome did not affect the efficacy of cyclosporin. ${ }^{93}$ In another clinical study, cyclosporin significantly improved patients' psoriasis symptoms and this was associated with increased transcription activity of TGF $\beta 1$ at the end of treatment in those with or without diabetes, and with or without metabolic syndrome. ${ }^{112}$ Through inhibition of the enzyme cyclophilin, cyclosporin has shown beneficial effects on liver fibrosis and cirrhosis in some patients. However, calcineurin-related toxicity has limited the possibility of long-term therapy and has required that dosages be kept low. ${ }^{113}$

\section{Apremilast}

Apremilast is a phosphodiesterase 4 inhibitor shown to be clinically effective in patients with psoriasis and/or psoriatic arthritis and also acts as a metabolic modulator. In individual cases, apremilast was shown to improve glucose metabolism ${ }^{114}$ and lipid profile. ${ }^{115}$ Similar findings were reported in a 1-year open observational study (Table 3). ${ }^{94}$

\section{Fumaric Acid Esters Including Dimethyl Fumarate}

DMF, and its active metabolite monomethylfumarate (MMF), are of particular interest in the context of this review due to their unique multiple mechanisms of action (Figure 4). ${ }^{102,103,105,116,117}$ These include immunomodulatory and anti-inflammatory mechanisms that are potentially advantageous in psoriatic patients with comorbid NAFLD (Table 3). ${ }^{116}$ For example, DMF/MMF regulates cellular responses to oxidative stress by modulating intracellular glutathione levels. ${ }^{102} \mathrm{DMF} / \mathrm{MMF}$ also reduces oxidative stress through activation of Nrf2 (nuclear factor erythroid 2-related factor 2) which stimulates cytoprotective and antiinflammatory factors such as HO-1 (heme oxygenase-1);$103,106,116$ and through inhibiting genes regulated by the transcription factor HIF-1 $\alpha$ (hypoxia-inducible factor 1-alpha) and STAT3/STAT1 (signal transducer and activator of transcription) pathways. ${ }^{116} \mathrm{MMF}$ is an agonist for hydroxy-carboxylic acid receptor 2 (HCA2/ GPR109A [G proteincoupled receptor 109A]) which inhibits neutrophil adhesion and recruitment by COX-1 (cyclooxygenase 1) and PGE2 


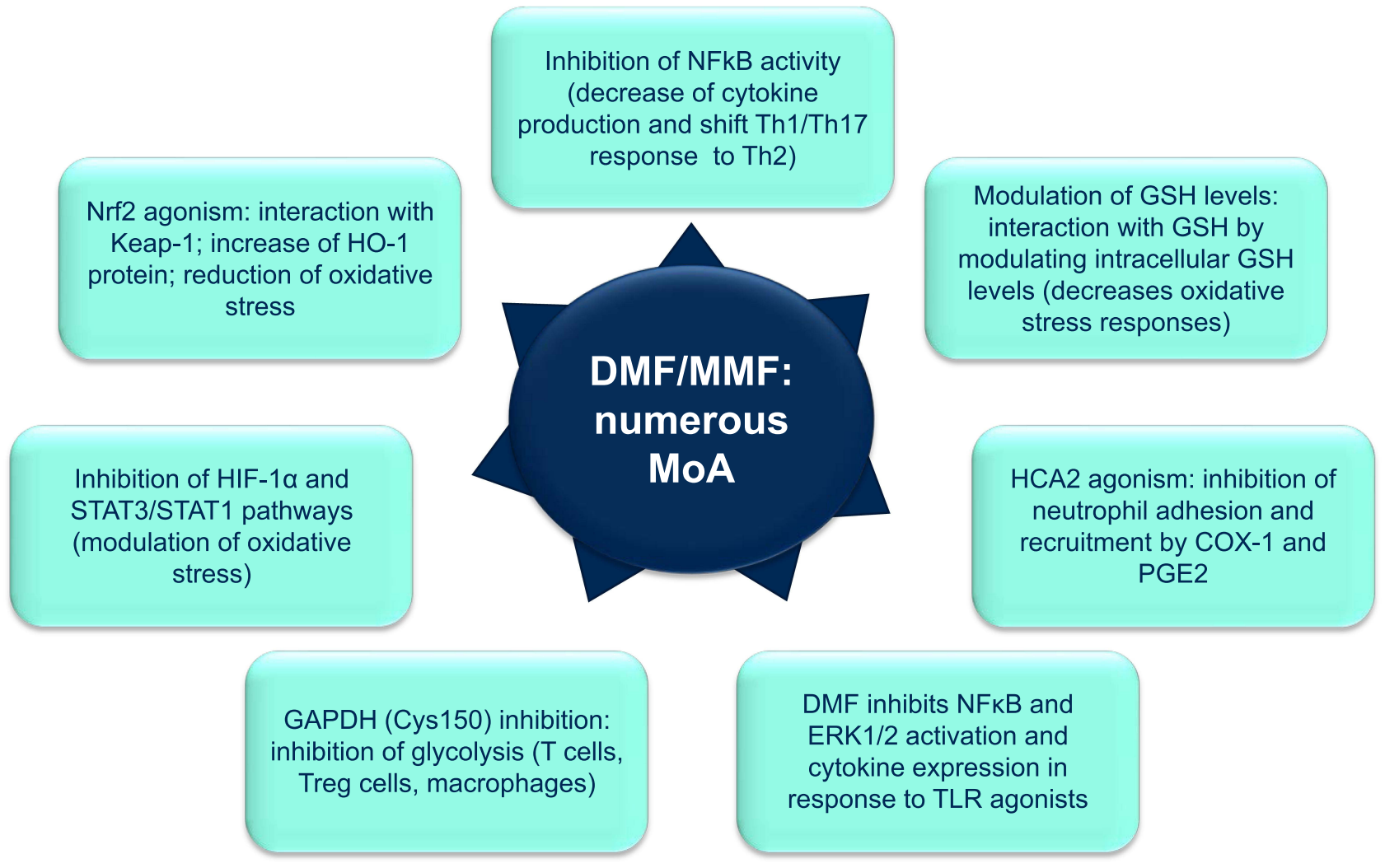

Figure 4 Proposed mechanisms of action of dimethyl fumarate/monomethyl fumarate (DMF/MMF). Note: Data from these studies. ${ }^{102,103,105,116,117}$

(prostaglandin E2). ${ }^{116}$ Fumaric acid esters significantly reduced total cholesterol, low-density lipoprotein and apolipoprotein $\mathrm{B}$ levels in a prospective trial involving psoriasis patients. ${ }^{96}$ In animal models, DMF has shown potential to ameliorate acetaminophen-induced hepatic injury in mice, ${ }^{107}$ as well as liver ischemia/reperfusion injury in rats. ${ }^{104}$ Improvement of liver function and anti-oxidant status might prove to be a promising treatment approach in patients with psoriasis and comorbid NAFLD.

\section{TNF Inhibitors}

Adalimumab was shown to reduce key markers of systemic inflammation including glycoprotein acetylation, CRP, IL-6 and TNF and this was associated with beneficial cardiovascular effects such as improved endothelial dysfunction as measured by flow-mediated dilation. $^{95,96}$ TNF- $\alpha$ inhibitors have been reported to improve insulin resistance in patients with rheumatoid arthritis ${ }^{118,119}$ and ankylosing spondylitis, ${ }^{18,120}$ but not in obese patients with either type 2 diabetes $^{121}$ or metabolic syndrome. ${ }^{122,123}$ Seitz et al investigated the impact of TNF- $\alpha$ inhibitors on the presence of liver fibrosis in patients with psoriatic arthritis and rheumatoid arthritis treated with methotrexate. ${ }^{124}$ Patients with psoriatic arthritis had a higher incidence of liver steatosis and hyperlipidemia and in this study. TNF- $\alpha$ inhibitors exerted a protective effect against the development of liver fibrosis.

\section{Secukinumab (Anti-IL-I7)}

Secukinumab has been shown to have neutral effects on fasting plasma glucose, lipid parameters and liver enzymes, while reducing levels of CRP, a marker for systemic inflammation. It was also associated with a reduction in markers of oxidative stress. Secukinumab produced greater improvement in arterial elasticity, coronary artery function and myocardial deformation indices compared with methotrexate and cyclosporin. However, no data are available on the impact of these effects on liver function. ${ }^{97,98}$

\section{Ustekinumab (Anti-IL-I2/23)}

Ustekinumab significantly decreases pro-inflammatory cytokines, such as TNF- $\alpha$, IL-1b, IL-17a and IL-6. 
VCAM-1 was significantly reduced by ustekinumab at 12 weeks, although this effect was not sustained at 1 year. Overall, ustekinumab transiently reduced aortic vascular inflammation at 12 weeks and, longer term, produced a more durable reduction in inflammatory cytokines associated with cardiovascular disease. ${ }^{101}$ No published studies have investigated the impact of this effect on liver inflammation and function.

\section{Conclusions}

NAFLD is an increasingly prevalent and clinically important comorbidity occurring in up to $65 \%$ of patients with psoriasis. The occurrence of NAFLD in psoriasis can have significant morbidity and mortality potential. There are multiple pathophysiological pathways that link psoriasis with NAFLD, in particular systemic inflammation and insulin resistance. Reducing systemic inflammatory burden may provide an opportunity to reduce the progression or even ameliorate NAFLD.

A number of conventional drugs used in the treatment of psoriasis are associated with hepatotoxic risk. Most evidence relates to use of methotrexate which, along with other NAFLD-promoting drugs, is best avoided in psoriasis patients with clinical risk factors for hepatotoxicity or established NAFLD. Despite the expectation that systemic psoriasis treatments might reduce the progression of or even ameliorate NAFLD by targeting pro-inflammatory cytokines, clinical data for direct hepatoprotective effects of these therapies are relatively scarce. Through its pleiotropic mechanisms of action contributing to its anti-inflammatory activity, DMF may have additional hepatoprotective effects of possible advantage in psoriatic patients with NAFLD.

However, real-world data on the effects of DMF in patients with psoriasis and concomitant NAFLD is currently lacking, and further studies with DMF and other systemic psoriasis therapies in routine clinical practice would be needed to inform therapeutic decision-making strategies for psoriasis patients with NAFLD.with DMF and other systemic psoriasis therapies in routine clinical practice would be needed to inform therapeutic decisionmaking strategies for psoriasis patients with NAFLD.

\section{Acknowledgments}

The authors thank Dr Rob Furlong and Dr Steve Clissold on behalf of Content Ed Net, Spain for editorial support, which was sponsored by Almirall, Barcelona, Spain, and performed in line with Good Publishing Practice (GPP-3) guidelines.

\section{Funding}

This article was supported by an unrestricted educational grant from Almirall, Barcelona, Spain.

\section{Disclosure}

DMWB is a consultant/speaker for AbbVie, Almirall, Celgene, Eli Lilly, Galderma, Janssen, LEO Pharma, Novartis, and Regeneron/Sanofi Genzyme. IK is an employee of Almirall, Barcelona, Spain. SP is a consultant/ speaker for AbbVie, Almirall, Celgene, Eli Lilly, Galderma, Janssen, LEO Pharma, Novartis, UCB, and Pfizer. The authors report no other conflicts of interest in this work.

\section{References}

1. Armstrong AW, Mehta MD, Schupp CW, et al. Psoriasis prevalence in adults in the United States. JAMA Dermatol. 2021;157 (8):940-946. doi:10.1001/jamadermatol.2021.2007

2. Griffiths CE, Barker JN. Pathogenesis and clinical features of psoriasis. Lancet. 2007;370:263-271. doi:10.1016/S0140-6736 (07)61128-3

3. Balato N, Megna M, Palmisano F, et al. Psoriasis and sport: a new ally? J Eur Acad Dermatol Venereol. 2015;29(3):515-520. doi: $10.1111 /$ jdv. 12607

4. Gisondi P, Bellinato F, Girolomoni G, et al. Pathogenesis of chronic plaque psoriasis and its intersection with cardio-metabolic comorbidities. Front Pharmacol. 2020;11:117. doi:10.3389/ fphar.2020.00117

5. Prussick RB, Miele L. Non-alcoholic fatty liver disease in patients with psoriasis: a consequence of systemic inflammatory burden? $\mathrm{Br}$ J Dermatol. 2018;179(1):16-29. doi:10.1111/bjd.16239

6. Lønnberg AS, Skov L. Co-morbidity in psoriasis: mechanisms and implications for treatment. Expert Rev Clin Immunol. 2017;13:27-34. doi:10.1080/1744666X.2016.1213631

7. Elmets CA, Leonardi CL, Davis DMR, et al. Joint AAD-NPF guidelines of care for the management and treatment of psoriasis with awareness and attention to comorbidities. $\mathrm{J}$ Am Acad Dermatol. 2019;80:1073-1113. doi:10.1016/j.jaad.2018.11.058

8. Sheka AC, Adeyi O, Thompson J, et al. Nonalcoholic steatohepatitis: a review. JAMA. 2020;323(12):1175-1183. doi:10.1001/ jama.2020.2298

9. Vernon G, Baranova A, Younossi ZM. Systematic review: the epidemiology and natural history of non-alcoholic fatty liver disease and non-alcoholic steatohepatitis in adults. Aliment Pharmacol Ther. 2011;34(3):274-285. doi:10.1111/j.1365-2036.2011.04724.x

10. Younossi ZM. The epidemiology of nonalcoholic steatohepatitis. Clin Liver Dis (Hoboken). 2018;11(4):92-94. doi:10.1002/cld.710

11. Belinchón-Romero I, Bellot P, Romero-Pérez D, et al. Non-alcoholic fatty liver disease is associated with bacterial translocation and a higher inflammation response in psoriatic patients. Sci Rep. 2021;11(1):8593. doi:10.1038/s41598-021-88043-8

12. Rinella ME. Nonalcoholic fatty liver disease: a systematic review. JAMA. 2015;313(22):2263-2273. doi:10.1001/jama.2015.5370

13. Adams LA, Lymp JF, St Sauver J, et al. The natural history of nonalcoholic fatty liver disease: a population-based cohort study. Gastroenterology. 2005;129(1):113-121. doi:10.1053/j.gastro.20 05.04.014 
14. Harrison SA, Di Bisceglie AM. Advances in the understanding and treatment of nonalcoholic fatty liver disease. Drugs. 2003;63 (22):2379-2394. doi:10.2165/00003495-200363220-00001

15. Magdaleno-Tapial J, Valenzuela-Oñate C, Ortiz-Salvador JM, et al. Prevalence of non-alcoholic fatty liver and liver fibrosis in patients with moderate-severe psoriasis: a cross-sectional cohort study. Australas J Dermatol. 2020;61(2):105-109. doi:10.1111/ ajd.13175

16. Ortolan A, Lorenzin M, Tadiotto G, et al. Metabolic syndrome, non-alcoholic fatty liver disease and liver stiffness in psoriatic arthritis and psoriasis patients. Clin Rheumatol. 2019;38 (10):2843-2850. doi:10.1007/s10067-019-04646-7

17. Olveira A, Herranz P, Montes ML. Psoriasis and fatty liver: a harmful synergy. Rev Esp Enferm Dig. 2019;111(4):314-319. doi:10.17235/reed.2019.6263/2019

18. Hamaguchi M, Kojima T, Takeda N, et al. The metabolic syndrome as a predictor of nonalcoholic fatty liver disease. Ann Intern Med. 2005;143(10):722-728. doi:10.7326/0003-4819-14310-200511150-00009

19. Chalasani N, Younossi Z, Lavine JE, et al. The diagnosis and management of non-alcoholic fatty liver disease: practice guideline by the American Gastroenterological Association, American Association for the Study of Liver Diseases, and American College of Gastroenterology. Gastroenterology. 2012;142 (7):1592-1609. doi:10.1053/j.gastro.2012.04.001

20. Golabi P, Otgonsuren M, de Avila L, et al. Components of metabolic syndrome increase the risk of mortality in nonalcoholic fatty liver disease (NAFLD). Medicine (Baltimore). 2018;97(13): e0214. doi:10.1097/MD.0000000000010214

21. Takaki A, Kawai D, Yamamoto K. Multiple hits, including oxidative stress, as pathogenesis and treatment target in non-alcoholic steatohepatitis (NASH). Int J Mol Sci. 2013;14(10):20704 20728. doi:10.3390/ijms141020704

22. Gisondi P, Galvan A, Idolazzi L, et al. Management of moderate to severe psoriasis in patients with metabolic comorbidities. Front Med (Lausanne). 2015;2:1. doi:10.3389/fmed.2015.00001

23. Vilar-Gomez E, Martinez-Perez Y, Calzadilla-Bertot L, et al. Weight loss through lifestyle modification significantly reduces features of nonalcoholic steatohepatitis. Gastroenterology. 2015;149(2):367-378. doi:10.1053/j.gastro.2015.04.005

24. Lonardo A, Loria P, Carulli N. Concurrent non-alcoholic steatohepatitis and psoriasis. Report of three cases from the POLI.ST.E. N.A. study. Dig Liver Dis. 2001;33(1):86-87. doi:10.1016/S15908658(01)80144-4

25. Gisondi P, Targher G, Zoppini G, et al. Non-alcoholic fatty liver disease in patients with chronic plaque psoriasis. $J$ Hepatol. 2009;51(4):758-764. doi:10.1016/j.jhep.2009.04.020

26. Gisondi P, Barba E, Girolomoni G. Non-alcoholic fatty liver disease fibrosis score in patients with psoriasis. $J$ Eur Acad Dermatol Venereol. 2016;30(2):282-287. doi:10.1111/jdv.13456

27. van der Voort EA, Koehler EM, Dowlatshahi EA, et al. Psoriasis is independently associated with nonalcoholic fatty liver disease in patients 55 years old or older: results from a population-based study. J Am Acad Dermatol. 2014;70(3):517-524. doi:10.1016/j. jaad.2013.10.044

28. Madanagobalane S, Anandan S. The increased prevalence of nonalcoholic fatty liver disease in psoriatic patients: a study from South India. Australas J Dermatol. 2012;53(3):190-197. doi:10.1111/j.1440-0960.2012.00905.x

29. Abedini R, Salehi M, Lajevardi V, et al. Patients with psoriasis are at a higher risk of developing nonalcoholic fatty liver disease. Clin Exp Dermatol. 2015;40(7):722-727. doi:10.1111/ ced. 12672
30. Ogdie A, Grewal SK, Noe MH, et al. Risk of incident liver disease in patients with psoriasis, psoriatic arthritis, and rheumatoid arthritis: a population-based study. J Invest Dermatol. 2018;138(4):760-767. doi:10.1016/j.jid.2017.10.024

31. Candia R, Ruiz A, Torres-Robles R, et al. Risk of non-alcoholic fatty liver disease in patients with psoriasis: a systematic review and meta-analysis. J Eur Acad Dermatol Venereol. 2015;29 (4):656-662. doi:10.1111/jdv.12847

32. Phan K, Onggo J, Charlton O, et al. Relationship between psoriasis and non-alcoholic fatty liver disease - Updated systematic review and adjusted meta-analysis. Australas $J$ Dermatol. 2019;60(4):e352-e355. doi:10.1111/ajd.13015

33. Yang YW, Keller JJ, Lin HC. Medical comorbidity associated with psoriasis in adults: a population-based study. Br J Dermatol. 2011;165(5):1037-1043. doi:10.1111/j.1365-2133.2011.10494.x

34. Gandha N, Wibawa LP, Jacoeb TNA, et al. Correlation between psoriasis severity and nonalcoholic fatty liver disease degree measured using controlled attenuation parameter. Psoriasis (Auckl). 2020;10:39-44. doi:10.2147/PTT.S272286

35. Roberts KK, Cochet AE, Lamb PB, et al. The prevalence of NAFLD and NASH among patients with psoriasis in a tertiary care dermatology and rheumatology clinic. Aliment Pharmacol Ther. 2015;41(3):293-300. doi:10.1111/apt.13042

36. Romero-Pérez D, Belinchón-Romero I, Bellot $\mathrm{P}$, et al. Nonalcoholic fatty liver disease puts patients with psoriasis at greater cardiovascular risk. Australas J Dermatol. 2019;60:e304e310. doi:10.1111/ajd.13098

37. National Guideline Centre (UK). Non-alcoholic fatty liver disease: assessment and management. London: National Institute for Health and Care Excellence (UK); 2016. (NICE Guideline, No. 49.) 5, Risk factors for NAFLD. Available from: https://www.ncbi.nlm.nih.gov/ books/NBK384735. Accessed November 10, 2021.

38. Friedman SL, Neuschwander-Tetri BA, Rinella M, et al. Mechanisms of NAFLD development and therapeutic strategies. Nat Med. 2018;24(7):908-922. doi:10.1038/s41591-018-0104-9

39. Kamiya K, Kishimoto M, Sugai J, et al. Risk factors for the development of psoriasis. Int $J$ Mol Sci. 2019;20:4347. doi:10.3390/ijms20184347

40. Ganzetti G, Campanati A, Molinelli E, et al. Psoriasis, non-alcoholic fatty liver disease, and cardiovascular disease: three different diseases on a unique background. World J Cardiol. 2016;8 (2):120-131. doi:10.4330/wjc.v8.i2.120

41. Grželj J, Mlinarič-Raščan I, Marko PB, et al. Polymorphisms in GNMT and DNMT3b are associated with methotrexate treatment outcome in plaque psoriasis. Biomed Pharmacother. 2021;138:111456. doi:10.1016/j.biopha.2021.111456

42. Heitmann J, Frings VG, Geier A, et al. Non-alcoholic fatty liver disease and psoriasis - is there a shared proinflammatory network? J Dtsch Dermatol Ges. 2021;19(4):517-528.

43. Harden JL, Krueger JG, Bowcock AM. The immunogenetics of psoriasis: a comprehensive review. J Autoimmun. 2015;64:66-73. doi:10.1016/j.jaut.2015.07.008

44. Liang Y, Sarkar MK, Tsoi LC, et al. Psoriasis: a mixed autoimmune and autoinflammatory disease. Curr Opin Immunol. 2017;49:1-8. doi:10.1016/j.coi.2017.07.007

45. Rendon A, Schäkel K. Psoriasis pathogenesis and treatment. Int J Mol Sci. 2019;20(6):E1475. doi:10.3390/ijms20061475

46. Kagami S, Rizzo HL, Lee JJ, et al. Circulating Th17, Th22, and Th1 cells are increased in psoriasis. J Invest Dermatol. 2010;130 (5):1373-1383. doi:10.1038/jid.2009.399

47. Lowes MA, Suárez-Fariñas M, Krueger JG. Immunology of psoriasis. Annu Rev Immunol. 2014;32:227-255. doi:10.1146/ annurev-immunol-032713-120225 
48. Mantovani A, Gisondi P, Lonardo A, et al. Relationship between non-alcoholic fatty liver disease and psoriasis: a novel hepatodermal axis? Int J Mol Sci. 2016;17(2):217. doi:10.3390/ijms17 020217

49. Hawkes JE, Yan BY, Chan TC, et al. Discovery of the IL-23/IL17 signaling pathway and the treatment of psoriasis. J Immunol. 2018;201(6):1605-1613. doi:10.4049/jimmunol.1800013

50. Ruiz de Morales JMG, Puig L, Daudén E, et al. Critical role of interleukin (IL)-17 in inflammatory and immune disorders: an updated review of the evidence focusing on controversies. Autoimmun Rev. 2020;19(1):102429. doi:10.1016/j.autrev.2019.102429

51. Streba LA, Vere CC, Rogoveanu I, et al. Nonalcoholic fatty liver disease, metabolic risk factors, and hepatocellular carcinoma: an open question. World J Gastroenterol. 2015;21(14):4103-4110. doi:10.3748/wjg.v21.i14.4103

52. Carr RM, Oranu A, Khungar V. Nonalcoholic fatty liver disease: pathophysiology and management. Gastroenterol Clin North Am. 2016;45(4):639-652. doi:10.1016/j.gtc.2016.07.003

53. Anstee QM, Daly AK, Day CP. Genetic modifiers of non-alcoholic fatty liver disease progression. Biochim Biophys Acta. 2011;1812(11):1557-1566. doi:10.1016/j.bbadis.2011.07.017

54. Eslam M, Valenti L, Romeo S. Genetics and epigenetics of NAFLD and NASH: clinical impact. $J$ Hepatol. 2018;68 (2):268-279. doi:10.1016/j.jhep.2017.09.003

55. Yousaf A, Raiker R, Davis SM, et al. Association between psoriasis, psoriatic arthritis and gastrointestinal disease. Wien Klin Wochenschr. 2021;133:586-593. doi:10.1007/s00508-020-01740-8

56. Angulo P, Lindor KD. Non-alcoholic fatty liver disease. $J$ Gastroenterol Hepatol. 2002;17(Suppl):S186-190. doi:10.1046/ j.1440-1746.17.s1.10.x

57. Ganzetti G, Campanati A, Offidani A. Non-alcoholic fatty liver disease and psoriasis: so far, so near. World J Hepatol. 2015;7 (3):315-326. doi:10.4254/wjh.v7.i3.315

58. Young S, Tariq R, Provenza J, et al. Prevalence and profile of nonalcoholic fatty liver disease in lean adults: systematic review and meta-analysis. Hepatol Commun. 2020;4(7):953-972. doi:10.1002/hep4.1519

59. Meli R, Mattace Raso G, Calignano A. Role of innate immune response in non-alcoholic fatty liver disease: metabolic complications and therapeutic tools. Front Immunol. 2014;5:177. doi:10. 3389/fimmu.2014.00177

60. Jarrar M, Baranova A, Collantes R, et al. Adipokines and cytokines in non-alcoholic fatty liver disease. Aliment Pharmacol Ther. 2008;27:412-421. doi:10.1111/j.1365-2036.2007.03586.x

61. Carrascosa JM, Bonanad C, Dauden E, et al. Psoriasis and nonalcoholic fatty liver disease. Actas Dermosifiliogr. 2017;108 (6):506-514. doi:10.1016/j.ad.2016.12.017

62. Martin DA, Towne JE, Kricorian G, et al. The emerging role of IL-17 in the pathogenesis of psoriasis: preclinical and clinical findings. J Invest Dermatol. 2013;133:17-26. doi:10.1038/jid. 2012.194

63. Theocharidou E, Papademetriou M, Reklou A, et al. The role of PCSK9 in the pathogenesis of non-alcoholic fatty liver disease and the effect of PCSK9 inhibitors. Curr Pharm Des. 2018;24 (31):3654-3657. doi:10.2174/1381612824666181010123127

64. Luan C, Chen X, Zhu Y, et al. Potentiation of psoriasis-like inflammation by PCSK9. J Invest Dermatol. 2019;139(4):859867. doi:10.1016/j.jid.2018.07.046

65. Piaserico S, Messina F, Russo FP. Managing psoriasis in patients with HBV or HCV infection: practical considerations. Am J Clin Dermatol. 2019;20:829-845. doi:10.1007/s40257-019-00457-3

66. Taylor WJ, Korendowych E, Nash P, et al. Drug use and toxicity in psoriatic disease: focus on methotrexate. $J$ Rheumatol. 2008;35:1454-1457.
67. Shetty A, Cho W, Alazawi W, et al. Methotrexate hepatotoxicity and the impact of nonalcoholic fatty liver disease. Am J Med Sci. 2017;354(2):172-181. doi:10.1016/j.amjms.2017.03.014

68. Nast A, Gisondi P, Ormerod AD, et al. European S3-guidelines on the systemic treatment of psoriasis vulgaris - update 2015 - short version-EDF in cooperation with EADV and IPC. J Eur Acad Dermatol Venereol. 2015;29(12):2277-2294. doi:10.1111/jdv.13 354

69. Balak DMW, Gerdes S, Parodi A, et al. Long-term safety of oral systemic therapies for psoriasis: a comprehensive review of the literature. Dermatol Ther (Heidelb). 2020;10(4):589-613. doi:10.1007/s13555-020-00409-4

70. Gelfand JM, Wan J, Zhang H, et al. Risk of liver disease in patients with psoriasis, psoriatic arthritis, and rheumatoid arthritis receiving methotrexate: a population-based study. J Am Acad Dermatol. 2021;84(6):1636-1643. doi:10.1016/j.jaad.2021.02.019

71. Bath RK, Brar NK, Forouhar FA, et al. A review of methotrexateassociated hepatotoxicity. J Dig Dis. 2014;15(10):517-524. doi:10.1111/1751-2980.12184

72. Ezhilarasan D. Hepatotoxic potentials of methotrexate: understanding the possible toxicological molecular mechanisms. Toxicology. 2021;458:152840. doi:10.1016/j.tox.2021.152840

73. European Medicines Agency. Summary of product characteristics. Nordimet (methotrexate) $7.5-25 \mathrm{mg}$ solution for injection in prefilled pen. Available from: https://www.ema.europa.eu/en/docu ments/product-information/nordimet-epar-product-information en.pdf. Accessed November 10, 2021.

74. Electronic Medicines Compendium (EMC). Sandimmun concentrate for solution for infusion $50 \mathrm{mg} / \mathrm{mL} ; 2020$. Available from: https://www.medicines.org.uk/emc/product/1036/smpc. Accessed November 10, 2021.

75. Prussick R, Prussick L, Nussbaum D. Nonalcoholic fatty liver disease and psoriasis: what a dermatologist needs to know. J Clin Aesthet Dermatol. 2015;8(3):43-45.

76. European Association for the Study of the Liver (EASL); European Association for the Study of Diabetes (EASD); European Association for the Study of Obesity (EASO). EASLEASD-EASO clinical practice guidelines for the management of non-alcoholic fatty liver disease. J Hepatol. 2016;64(6):13881402. doi:10.1016/j.jhep.2015.11.004

77. Electronic Medicines Compendium (EMC). Skilarence $30 \mathrm{mg}$ gastro-resistant tablets; 2020. Available from: www.medicines. org.uk/emc/product/752/smpc\#gref. Accessed November 10, 2021.

78. LiverTox: clinical and research information on drug-induced liver injury [Internet]. Bethesda (MD): National Institute of Diabetes and Digestive and Kidney Diseases. Available from: https://eur opepmc.org/article/NBK/NBK548013. Accessed November 10, 2021.

79. Roenigk HH, Callen JP, Guzzo CA, et al. Effects of Acitretin on the liver. J Am Acad Dermatol. 1999;41(4):584-588.

80. Dunn LK, Gaar LR, Yentzer BA, et al. Acitretin in dermatology: a review. J Drugs Dermatol. 2011;10:772-782.

81. Ghabril M, Bonkovsky HL, Kum C, et al. Liver injury from tumor necrosis factor-alpha antagonists: analysis of thirty-four cases. Clin Gastroenterol Hepatol. 2013;11:558-564.

82. Rossi RE, Parisi I, Despott EJ, et al. Anti-tumour necrosis factor agent and liver injury: literature review, recommendations for management. World J Gastroenterol. 2014;20(46):17352-17359. doi:10.3748/wjg.v20.i46.17352

83. Mikhaylov D, Hashim PW, Nektalova T, et al. Systemic psoriasis therapies and comorbid disease in patients with psoriasis: a review of potential risks and benefits. J Clin Aesthet Dermatol. 2019;12(6):46-54. 
84. Wu MY, Yu CL, Yang SJ, et al. Change in body weight and body mass index in psoriasis patients receiving biologics: a systematic review and network meta-analysis. J Am Acad Dermatol. 2020;82 (1):101-109. doi:10.1016/j.jaad.2019.07.103

85. Llamas-Velasco M, Concha-Garzon MJ, Garcia-Diez A, et al. Liver injury in psoriasis patients receiving ustekinumab: a retrospective study of 44 patients treated in the clinical practice setting. Actas Dermosifiliogr. 2015;106(6):470-476. doi:10.1016/j. ad.2015.02.002

86. Gebreselassie A, Aduli F, Howell CD. Rheumatologic diseases and the liver. Clin Liver Dis. 2019;23(2):247-261. doi:10.1016/j. cld.2018.12.007

87. Polat Ekinci A, Bölük KN, Babuna Kobaner G. Secukinumab and Acitretin as a combination therapy for three clinical forms of severe psoriasis in multi-drug refractory patients: a case series of high efficacy and safety profile. Dermatol Ther. 2021;34(1): e14704. doi:10.1111/dth.14704

88. Gisondi P, Conti A, Galdo G, et al. Ustekinumab does not increase body mass index in patients with chronic plaque psoriasis: a prospective cohort study. $B r$ J Dermatol. 2013;168 (5):1124-1127. doi:10.1111/bjd.12235

89. Krahel JA, Baran A, Kamiński TW, et al. Methotrexate decreases the level of PCSK9-a novel indicator of the risk of proatherogenic lipid profile in psoriasis. the preliminary data. J Clin Med. 2020;9 (4):910. doi:10.3390/jcm9040910

90. Kiluk P, Baran A, Kaminski TW, et al. The level of FGF 21 as a new risk factor for the occurrence of cardiometabolic disorders amongst the psoriatic patients. J Clin Med. 2019;8(12):2206. doi:10.3390/jcm8122206

91. Mangoni AA, Zinellu A, Sotgia S, et al. Protective effects of methotrexate against proatherosclerotic cytokines: a review of the evidence. Mediators Inflamm. 2017;2017:9632846. doi:10.1155/ 2017/9632846

92. Mangoni AA, Tommasi S, Zinellu A, et al. Methotrexate and vasculoprotection: mechanistic insights and potential therapeutic applications in old age. Curr Pharm Des. 2019;25(39):41754184. doi:10.2174/1381612825666191112091700

93. Michalska-Bańkowska A, Grabarek B, Wcisło-Dziadecka D, et al. The impact of diabetes and metabolic syndromes to the effectiveness of cyclosporine a pharmacotherapy in psoriatic patients. Dermatol Ther. 2019;32(3):e12881. doi:10.1111/dth.12881

94. Mazzilli S, Lanna C, Chiaramonte C, et al. Real life experience of apremilast in psoriasis and arthritis psoriatic patients: preliminary results on metabolic biomarkers. J Dermatol. 2020;47(6):578582. doi:10.1111/1346-8138.15293

95. Mehta NN, Shin DB, Joshi AA, et al. Effect of 2 psoriasis treatments on vascular inflammation and novel inflammatory cardiovascular biomarkers: a randomized placebo-controlled trial. Circ Cardiovasc Imaging. 2018;11(6):e007394. doi:10.11 61/CIRCIMAGING.117.007394

96. Holzer G, Hoke M, Sabeti-Sandor S, et al. Disparate effects of Adalimumab and fumaric acid esters on cardiovascular risk factors in psoriasis patients: results from a prospective, randomized, observer-blinded head-to-head trial. J Eur Acad Dermatol Venereol. 2021;35(2):441-449. doi:10.1111/jdv.16635

97. Gelfand JM, Shin DB, Duffin KC, et al. A randomized placebocontrolled trial of secukinumab on aortic vascular inflammation in moderate-to-severe plaque psoriasis (VIP-S). J Invest Dermatol. 2020;140(9):1784-1793. doi:10.1016/j.jid.2020.01.025

98. Gerdes S, Pinter A, Papavassilis C, et al. Effects of secukinumab on metabolic and liver parameters in plaque psoriasis patients. $J$ Eur Acad Dermatol Venereol. 2020;34(3):533-541. doi:10.1111/ jdv. 16004

99. Ikumi K, Odanaka M, Shime H, et al. Hyperglycemia is associated with psoriatic inflammation in both humans and mice. J Invest Dermatol. 2019;139(6):1329-1338. doi:10.1016/j.jid.2019.01.029
100. Makavos G, Ikonomidis I, Andreadou I, et al. Effects of interleukin 17A inhibition on myocardial deformation and vascular function in psoriasis. Can $J$ Cardiol. 2020;36(1):100-111. doi:10.1016/j.cjca.2019.06.021

101. Gelfand JM, Shin DB, Alavi A, et al. A phase IV, randomized, doubleblind, placebo-controlled crossover study of the effects of ustekinumab on vascular inflammation in psoriasis (the VIP-U trial). $J$ Invest Dermatol. 2020;140(1):85-93. doi:10.1016/j.jid.2019.07.679

102. Zhu K, Mrowietz U. Inhibition of dendritic cell differentiation by fumaric acid esters. J Invest Dermatol. 2001;116(2):203-208. doi:10.1046/j.1523-1747.2001.01159.x

103. Peng H, Guerau-de-arellano M, Mehta VB, et al. Dimethyl fumarate inhibits dendritic cell maturation via nuclear factor $\kappa \mathrm{B}(\mathrm{NF}$ $\kappa \mathrm{B})$ and extracellular signal-regulated kinase 1 and $2(\mathrm{ERK} 1 / 2)$ and mitogen stress-activated kinase 1 (MSK1) signaling. J Biol Chem. 2012;287(33):28017-28026. doi:10.1074/jbc.M112.383380

104. Takasu C, Vaziri ND, Li S, et al. Treatment with dimethyl fumarate ameliorates liver ischemia/reperfusion injury. World J Gastroenterol. 2017;23(25):4508-4516. doi:10.3748/wjg.v23.i25.4508

105. Kornberg MD, Bhargava P, Kim PM, et al. Dimethyl fumarate targets GAPDH and aerobic glycolysis to modulate immunity. Science. 2018;360(6387):449-453. doi:10.1126/science.aan4665

106. Brück J, Glocova I, Geisel J, et al. Dimethyl fumarate-induced IL17 low IFN- $\gamma$ low IL-4 + Th cells protect mice from severe encephalomyelitis. Eur J Immunol. 2018;48(9):1588-1591. doi:10.1002/eji.201747435

107. Abdelrahman RS, Abdel-Rahman N. Dimethyl fumarate ameliorates Acetaminophen-induced hepatic injury in mice dependent of Nrf-2/HO-1 pathway. Life Sci. 2019;217:251-260. doi:10.1016/j. lfs.2018.12.013

108. Dwivedi DK, Jena G, Kumar V. Dimethyl fumarate protects thioacetamide-induced liver damage in rats: studies on Nrf2, NLRP3, and NF-кB. J Biochem Mol Toxicol. 2020;34(6): e22476. doi:10.1002/jbt.22476

109. Korman NJ. Management of psoriasis as a systemic disease: what is the evidence? Br J Dermatol. 2020;182(4):840-848. doi:10. 1111/bjd.18245

110. Ridker PM, Everett BM, Pradhan A, et al. Low-dose methotrexate for the prevention of atherosclerotic events. $N$ Engl J Med. 2019;380(8):752-762. doi:10.1056/NEJMoa1809798

111. Karadag AS, Ertugrul DT, Kalkan G, et al. The effect of Acitretin treatment on insulin resistance, retinol-binding protein-4, leptin, and adiponectin in psoriasis vulgaris: a noncontrolled study. Dermatology. 2013;227(2):103-108. doi:10.1159/000351769

112. Michalska-Bańkowska A, Wcisło-Dziadecka D, Grabarek B, et al. Clinical and molecular evaluation of therapy with the use of cyclosporine $\mathrm{A}$ in patients with psoriasis vulgaris. Int $J$ Dermatol. 2019;58(4):477-482. doi:10.1111/ijd.14275

113. Ure DR, Trepanier DJ, Mayo PR, et al. Cyclophilin inhibition as a potential treatment for nonalcoholic steatohepatitis (NASH). Expert Opin Investig Drugs. 2020;29(2):163-178. doi:10.1080/ 13543784.2020.1703948

114. Lanna C, Cesaroni GM, Mazzilli S, et al. Small molecules, big promises: improvement of psoriasis severity and glucidic markers with apremilast: a case report. Diabetes Metab Syndr Obes. 2019;12:2685-2688. doi:10.2147/DMSO.S229549

115. Gualtierotti R, De Lucia O. Efficacy and metabolic effect on serum lipids of apremilast in psoriatic arthritis: a case report. $J$ Clin Med. 2019;8(3):398. doi:10.3390/jcm8030398

116. Brück J, Dringen R, Amasuno A, et al. A review of the mechanisms of action of dimethylfumarate in the treatment of psoriasis. Exp Dermatol. 2018;27(6):611-624. doi:10.1111/exd.13548

117. McGuire VA, Ruiz-Zorrilla Diez $\mathrm{T}$, Emmerich $\mathrm{CH}$, et al. Dimethyl fumarate blocks pro-inflammatory cytokine production via inhibition of TLR induced M1 and K63 ubiquitin chain formation. Sci Rep. 2016;6:31159. doi:10.1038/srep31159 
118. Kiortsis DN, Mavridis AK, Vasakos S, et al. Effects of infliximab treatment on insulin resistance in patients with rheumatoid arthritis and ankylosing spondylitis. Ann Rheum Dis. 2005;64(5):765766. doi:10.1136/ard.2004.026534

119. Gonzalez-Gay MA, De Matias JM, Gonzalez-Juanatey C, et al. Anti-tumor necrosis factor-alpha blockade improves insulin resistance in patients with rheumatoid arthritis. Clin Exp Rheumatol. 2006;24(1):83-86.

120. Miranda-Filloy JA, Llorca J, Carnero-López B, et al. TNF-alpha antagonist therapy improves insulin sensitivity in non-diabetic ankylosing spondylitis patients. Clin Exp Rheumatol. 2012;30 (6):850-855.

121. Dominguez H, Storgaard H, Rask-Madsen C, et al. Metabolic and vascular effects of tumor necrosis factor-alpha blockade with etanercept in obese patients with type 2 diabetes. $J$ Vasc Res. 2005;42(6):517-525. doi:10.1159/000088261
122. Bernstein LE, Berry J, Kim S, et al. Effects of etanercept in patients with the metabolic syndrome. Arch Intern Med. 2006;166:902-908. doi:10.1001/archinte.166.8.902

123. Wascher TC, Lindeman JH, Sourij H, et al. Chronic TNF- $\alpha$ neutralization does not improve insulin resistance or endothelial function in "healthy" men with metabolic syndrome. Mol Med. 2011;17(3-4):189-193. doi:10.2119/molmed.2010.00221

124. Seitz M, Reichenbach S, Möller B, et al. Hepatoprotective effect of tumour necrosis factor alpha blockade in psoriatic arthritis: a cross-sectional study. Ann Rheum Dis. 2010;69(6):1148-1150. doi:10.1136/ard.2009.116194

\section{Publish your work in this journal}

Psoriasis: Targets and Therapy is international, peer-reviewed, open access journal focusing on psoriasis, nail psoriasis, psoriatic arthritis and related conditions, identification of therapeutic targets and the optimal use of integrated treatment interventions to achieve improved outcomes and quality of life. Visit http://www.dovepress. com/testimonials.php to read real quotes from published authors. 